\title{
PRESUPPOSITION AND NEGATION
}

\author{
PIETER A.M. SEUREN
}

\begin{abstract}
This paper is an attempt to show that given the available observations on the behaviour of negation and presuppositions there is no simpler explanation than to assume that natural language has two distinct negation operators, the minimal negation which preserves presuppositions and the radical negation which does not. The three-valued logic emerging from this distinction, and especially its model-theory, are discussed in detail. It is, however, stressed that the logic itself is only epiphenomenal on the structures and processes involved in the interpretation of sentences.
\end{abstract}

Horn (1985) brings new observations to bear, related with metalinguistic uses of negation, and proposes a "pragmatic" ambiguity in negation to the effect that in descriptive (or "straight") use negation is the classical bivalent operator, whereas in metalinguistic use it is non-truthfunctional but only pragmatic. Van der Sandt (to appear) accepts Horn's observations but proposes a different solution: he proposes an ambiguity in the argument clause of the negation operator (which, for him, too, is classical and bivalent), according to whether the negation takes only the strictly asserted proposition or covers also the presuppositions, the (scalar) implicatures and other implications (in particular of style and register) of the sentence expressing that proposition. These theories are discussed at some length.

The three-valued analysis is defended on the basis of partly new observations, which do not seem to fit either Horn's or Van der Sandt's solution. It is then placed in the context of incremental discourse semantics, where both negations are seen to do the job of keeping increments out of the discourse domain, though each does so in its own specific way. The metalinguistic character of the radical negation is accounted for in terms of the incremental apparatus. The metalinguistic use of negation in denials of implicatures or implications of style and register is regarded as a particular form of minimal negation, where the negation denies not the proposition itself but the appropriateness of the use of an expression in it. This appropriateness negation is truth-functional and not pragmatic, but it applies to a particular, independently motivated, analysis of the argument clause.

The ambiguity of negation in natural language is different from the ordinary type of ambiguity found in the lexicon. Normally, lexical ambiguities are idiosyncratic, highly contingent, and unpredictable from language to language. In the case of negation, however, the two meanings are closely related, both truth-conditionally and incrementally. Moreover, the mechanism of discourse incrementation automatically selects the right meaning. These properties are taken to provide a sufficient basis for discarding the, otherwise valid, objection that negation is unlikely to be ambiguous because no known language makes a lexical distinction between the two readings.

\section{INTRODUCTION}

Ever since Strawson proposed $(1950,1952,1954)$ to regard the negation 
operator in natural language as presupposition-preserving there has been unclarity, in most of the literature, about the logical consequences of such a proposal. There was, and is, moreover, great unclarity regarding the relation between the semantics and the logic of this operator, and pragmatics, mainly of Gricean stock, has been frequently draughted to help out on dilemmas in the logical or semantic analyses of presupposition and negation. It is the purpose of this paper to provide greater clarity in the problems concerning the logic and the semantics of presupposition and negation in natural language, and to spell out what solutions are viable, given the empirical facts on the one hand and the constraints of logic on the other.

For a good understanding of what is attempted in this paper, a few methodological preliminaries will be useful. First, some comment is in order about the relation between logic and semantics. A distinction is made, here and elsewhere (e.g. Seuren 1985), between the logic and the semantics of natural language sentences in the following way. Semantics is understood as the empirical theory of how humans understand and interpret their uttered sentences the way they do. Semantics is thus part both of linguistics and of cognitive psychology. Logic is regarded as epiphenomenal upon the psycholinguistic structures and processes at work during the semantic construction and comprehension of linguistic utterances. In other words, no separate "logic component" is postulated. Whatever logic adheres to language emerges as a result of what goes on during semantic processing. This is not meant to imply that logic should not be taken seriously. On the contrary, logical soundness is one of the important independent constraining forces on any sound semantic theory. But logical properties do not necessarily count. Only if expressed in logical forms must logical, and hence truthconditional, distinctions be somehow reflected in the semantic analyses of sentences. It is important to realize that to specify the logic of language is to engage in some form of applied logic.

Another powerful constraining force for semantic theory is truthconditional soundness. But again, this does not mean that the adjectives semantic and truth-conditional should be taken to be co-extensive, as is standardly done in model-theoretic semantics, which takes the mathematical model-theory of logical calculi as the prototype of any semantic theory. There is no need to belittle the merits of the model-theoretic approach, which has greatly contributed to present-day semantics. Yet ("possible world") model-theory is hardly a plausible contender for the cognitive and linguistic problems ahead.

In our view, semantics for natural language covers, besides the straightforward truth-conditional aspects, also the speech act properties of sentences as well as everything to do with the processes of discourse incrementation, including the presuppositions in their different forms. The reason for this delimitation is that these are the properties of linguistic expressions 
that, together, produce the systematic contribution made by language towards the comprehension of sentences. (The remainder is contributed by what we usually call background knowledge.)

This paper thus contains linguistic as well as logical and cognitive analyses.

\section{THE EMPIRICAL ASPECT AND THE LOGICAL PROBLEM}

\subsection{Russell, Frege, Strawson}

The presupposition problem has its origin in two observations, made by philosophers and logicians of all ages. Both observations cause trouble for the age-old cherished Aristotelian Principle of the Excluded Third (PET). Classical (Aristotelian) logic is based on two basic principles, the Principle of Contradiction, which says that no sentence can be both true and not true, and PET. The Principle of Contradiction is basic to any form of logic and cannot be challenged. PET, however, is negotiable. Aristotle himself restricted PET to statements about the past and the present, excepting statements about the future, truth and falsity not being, in his view, well-defined for the future. (Past and present truths or falsehoods are forever fixed and beyond the reach of human intervention: the future, however, is not fixed and thus escapes the strict metaphysical necessity of past and present facts.) We will, in this paper, negotiate PET quite a bit further than has been deemed necessary or desirable in the mainstream of logical tradition.

The observations that cause trouble for PET are, in principle:

(a) One can speak intelligibly while assigning a property, by the use of a predicate, without there being a really existing object for the property to be assigned to.

(b) Negation in language has the tendency to preserve presuppositions, although negation as standardly defined in logic cancels all entailments of its argument proposition, except, of course, logical truths.

Both observations are demonstrated in Russell's (1905) famous (or perhaps one should say: hackneyed) pair of examples:

a. The present king of France is bald.

b. The present king of France is not bald.

In (1a) the property of baldness appears to be predicated, yet there is nothing for it to be predicated of. Sentence ( $1 \mathrm{~b}$ ) appears to imply that the present king of France's pate is hairy, and hence that there is something properly called "the present king of France" in the world to which it applies. Since (1a) implies the same thing, it would appear that this existential implication 
is preserved under negation.

Russell (1905) wished to preserve PET. His answer was, as is well known, twofold. First, he maintained that the definite description the present king of France has no status in logic but should be analyzed in terms of the existential quantifier (plus a uniqueness clause), so that (1a) will be analyzed as follows:

$$
\text { a. } \quad \exists x(K \circ F(x) \wedge \operatorname{Bald}(x) \wedge \forall y(K o F(y) \rightarrow y=x))
$$

This analysis makes (1a) unambiguously false in the present world, since there is no entity in this world that can be truthfully said to be, at present, king of France. Russell claimed, furthermore, that negation in language is like negation in standard logic, a truth-function that converts truth into falsity and vice versa. If (2a) is logically negated, i.e. with the negation operator prefixed to it ("external negation"), the resulting sentence will be true:

$$
\text { b. } \neg \exists \mathrm{x}(\mathrm{KoF}(\mathrm{x}) \wedge \operatorname{Bald}(\mathrm{x}) \wedge \forall \mathrm{y}(\mathrm{KoF}(\mathrm{y}) \sim \mathrm{y}=\mathrm{x}))
$$

It is, however, also possible to insert the negation operator in other positions in (2a), giving rise to so-called "internal negation". For reasons best known to themselves, human speakers prefer to read a sentence like (1b) with the negation stuck in just before the predicate "Bald", as in:

$$
\text { c. } \exists x(\operatorname{KoF}(x) \wedge \neg \operatorname{Bald}(x) \wedge \forall y(\operatorname{KoF}(y) \leftrightarrow y=x))
$$

This analysis saves PET, and keeps the logic standard, which is what Russell, and with him the great majority of logicians, wanted. It thus became the commonly accepted view regarding presuppositions and negation, and much of the effort spent in even quite recent publications on this subject is directly due to the wish to keep it so, despite the attacks that have been levelled against it.

The first big attack came from Strawson $(1950,1952,1954)$. Strawson rejected both of Russell's answers. In his view definite terms in sentences correspond exactly to (referring) terms in logical analysis, and negation is not classical but preserves presuppositional entailments. Moreover, a sentence whose presuppositions are not all true (fulfilled) lacks a truth-value, and thus plays no part in the logical truth-functions. This was also the dominant view if not proposed certainly considered in Frege (1892). In Frege's view, the extension ("Bedeutung" or designation) of a sentence is its truth-value. He moreover wanted logical analysis to be such that the extension (truthvalue) of a sentence can be computed by functional calculus from the extensions of its constituents. It follows that if a sentence contains a constituent that lacks an extension and yet is needed for the calculus, no value will 
result. Since definite terms are needed for the intended calculus, they must have an extension, i.e. a reference value in the world with respect to which the truth-value is computed. The lack of such an extension must result in the lack of a truth-value. A sentence thus "presupposes" the real existence of the reference values of its definite terms, no matter whether it is negated or not. Both (la) and ( $\mathrm{lb}$ ) thus entail, in virtue of this presupposition, the real existence of the present king of France.

The Frege-Strawson view is a direct attack on PET, given the possibility of sentences without a truth-value. It may be useful to mention that PET can be split up into two separate principles:

\section{Principle of the Excluded Third}

a. Full Valuation Principle: Every sentence of the language under analysis has a truth-value.

b. Bivalence Principle: There are exactly two truth-values: True and False.

It will be clear that the Frege-Strawson analysis denies the Full Valuation Principle, but not the Bivalence Principle.

Due, mainly, to a glaring lack of explicitness in both Frege's and Strawson's texts, considerable confusion arose in the subsequent literature about the precise consequences for logic if the Frege-Strawson analysis is accepted. That is, given that $a$ presupposes $b$, i.e. $a \gg b$, and thus, in this view, $a \mid=b$ and $\neg a \mid=b$ and $a$ lacks a truth-value when $b$ is false (or without a truth-value), and $b$ is not a logical or necessary truth, what consequences will this have for logic as we know it? The most helpful way of presenting this question was developed by Van Fraassen in a number of publications, especially (1971). Regrettably, the great value of Van Fraassen's way of analysing this question has not been recognized by the majority of those who have, over the past twenty or so years, contributed to the literature dealing with questions of presupposition and negation.

Van Fraassen works with valuations rather than with "possible worlds". A valuation is a complete set of truth-value assignments to the sentences of a language $L$, in particular the atomic sentences of $L$ (i.e. those sentences that are formed without any of the truth-functional operators of negation, conjunction and/or disjunction). A valuation $v_{n}$ thus defines a "world", or rather a state of affairs, to the extent that $L$ is able to specify it. If there are two truth-values and no gaps are allowed, and if, moreover, all the atomic sentences of $L$ are logically independent (there are no entailment relations among them), then, if $L$ has m logically independent atomic sentences, the number of possible valuations is $2^{\mathrm{m}}$. For example, if $L$ has just three logically independent atomic sentences, $a, b$ and $c$ (symbolised as $L$ $(a, b, c)$, the number of possible valuations is $2^{3}=8$ (we use "l" for truth and "2" for falsehood). 


\begin{tabular}{|l|l|l|l|l|l|l|l|l}
$U$ & $a$ & $b$ & $c$ & $\neg a$ & $\neg b$ & $\neg c$ & $a \wedge b$ & $\ldots$ etc \\
\hline $\mathrm{v}_{1}:$ & 1 & 1 & 1 & 2 & 2 & 2 & 1 & \\
$\mathrm{v}_{2}:$ & 2 & 1 & 1 & 1 & 2 & 2 & 2 & \\
$\mathrm{v}_{3}:$ & 1 & 2 & 1 & 2 & 1 & 2 & 2 & \\
$\mathrm{v}_{4}:$ & 2 & 2 & 1 & 1 & 1 & 2 & 2 & \\
$\mathrm{v}_{5}:$ & 1 & 1 & 2 & 2 & 2 & 1 & 1 & \\
$\mathrm{v}_{6}:$ & 2 & 1 & 2 & 1 & 2 & 1 & 2 & \\
$\mathrm{v}_{7}:$ & 1 & 2 & 2 & 2 & 1 & 1 & 2 & \\
$\mathrm{v}_{8}:$ & 2 & 2 & 2 & 1 & 1 & 1 & 2 &
\end{tabular}

Fig. I: Classical valuation space for $L(a, b, c)$.

Obviously, truth-functional compositions follow automatically. Thus, given that, for example, $\mathrm{v}_{3}(b)=2$, it follows that $\mathrm{v}_{3}(\neg b)=1$, or, given that $v_{3}(a)=1$ and $v_{3}(b)=2$, it follows that $v_{3}(a \wedge b)=2$.

It is clearly unrealistic to assume that the atomic sentences of any natural language are logically independent in the sense that for no atomic sentences $a$ and $b$ of some natural language, where $a \neq b, a \mid=b$. For example, English has two atomic sentences John has been murdered and John is dead, where the former entails the latter, and it seems hardly possible to imagine a language without such pairs of atomic sentences. Entailment relations, whether lexical or logical, reduce the number of admissible valuations. Thus, supposing that in $L(a, b, c) a I=b, v_{3}$ and $v_{7}$ are inadmissible because no world can exist where $a$ is true and $b$ is false. This entailment relation thus reduces the number of admissible valuations by two.

Now suppose that $a$ presuppose $b$ (i.e. $a>b$ ). In the Frege-Strawson analysis this means that for any $\mathrm{v}_{\mathrm{n}}$, if $\mathrm{v}_{\mathrm{n}}(a)=1$ or $2, \mathrm{v}_{\mathrm{n}}(b)=1$, and if, for any $v_{n}, v_{n}(b) \neq 1, a$ has no value for that $v_{n}$, as is shown in Fig. 2:

\begin{tabular}{l|l|l|l|l}
$U:$ & $a$ & $b$ & $c$ & $\ldots$ etc. \\
\hline $\mathrm{v}_{1}:$ & 1 & 1 & 1 & \\
$\mathrm{v}_{2}:$ & 2 & 1 & 1 & \\
$\mathrm{v}_{3}:$ & - & 2 & 1 & \\
$\mathrm{v}_{4}:$ & 1 & 1 & 2 & \\
$\mathrm{v}_{5}:$ & 2 & 1 & 2 & \\
$\mathrm{v}_{6}:$ & - & 2 & 2 &
\end{tabular}

Fig. 2.: Valuation space for $L(a, b, c)$, where $a>b$, in the Frege-Strawson analysis. 
The absence of a truth-value for $a$ in $v_{3}$ and $v_{6}$ is an infringement of PET, in particular the Full Valuation Principle. The common expression is that we have here a bivalent logic with gaps (Such gaps are an unwelcome complication for any standard Boolean semantics for the logical calculus, as we shall see in Section 2.1.) Note that the valuations $v_{3}, v_{4}, v_{7}$ and $v_{8}$ in Fig. 1 are now inadmissible. Instead, Fig. 2 contains the new valuations, with gaps, $v_{3}$ and $v_{6}$. What is important here is that the truth-functional operators will fail to yield values for any input which contains an unvalued sentence. This gives the following truth-tables for negation, conjunction and disjunction:

\begin{tabular}{|l|c|ccc|ccc|}
\hline & & \multicolumn{3}{|c|}{$\wedge \mathrm{q}$} & \multicolumn{3}{|c|}{$\vee \mathrm{q}$} \\
& $\mathrm{p}$ & 1 & 2 & - & 1 & 2 & - \\
\hline 2 & 1 & 1 & 2 & - & 1 & 1 & - \\
1 & 2 & 2 & 2 & - & 1 & 2 & - \\
- & - & - & - & - & - & - & - \\
\hline
\end{tabular}

Fig. 3: Truth-tables for bivalent calculus with gaps.

Clearly, these are simply the classical tables, with the extra provision that no value results when the input is not fully valued. This extra provision, however, is nothing new: it follows from the definition of the notion of function in set-theory. We shall see in Section 2 that the introduction of gaps in the field of valuations of a language $L$ is something quite different from the introduction of a third truth-value.

Apart from the fact that the occurrence of gaps causes certain complications of a general nature in the logic (complications, however, which can be dealt with), there is nothing logically wrong or even all that remarkable about a Strawsonian bivalent propositional calculus with gaps. The reason for rejecting it does not lie in its logical properties but in its empirical shortcomings. Strawson's criticism of Russell was inspired by worries about the empirical inadequacy of the Russell analysis of definite descriptions. These worries have proved to be well-founded (see in particular Seuren 1985: 214-7), and, as a result, the Russell analysis is now clearly out of favour. It is a little ironical to see that the same empirical axe that Strawson wielded now hit him.

\subsection{The entailment analysis}

What is at issue is, in part at least, very simple: it isn't true, at least not generally, that, if $a>>b, a$ is without a truth-value when $b$ fails to be true. We can say in perfect truth, e.g. 
It is true that normally speaking, let us say as a default, negative sentences are understood as preserving their presuppositions: they invite the inference that the presuppositions still hold, but, normally speaking, that inference can be overruled. This observation was brought to the fore around 1975 by a variety of authors (e.g. Boër \& Lycan 1976; Wilson 1975). These authors proceeded on the assumption that this presupposition-cancelling use of the negation operator, albeit marked by special intonation and possibly other features as well, is general in the sense that all presuppositions can be cancelled that way. They thus proposed that, from a strictly logical point of view, presuppositions are just entailments and are, therefore, cancelled under negation. What we identify as presuppositions are, in their view, only pragmatic phenomena, to do with reasonable expectations in speakerhearer interaction. Gricean pragmatics was thus invoked to account for presuppositional phenomena, in particular the invited inference character of presupposition under negation and other entailment cancelling operators. It is fair to say, however, that this pragmatic approach has not been successful (see in particular Van der Sandt 1982:50-88; 1988:50-86). What these authors proposed was a reversal to the classical bivalent system without gaps. If $a>b$, then classical valuation spaces, as in fig. 1, will do, with all valuations $v_{n}$ such that $v_{n}(a)=1$ and $v_{n}(b)=2$ being declared inadmissible. That is, $a>b$ is treated as though from a logico-semantic point of view it were simply $a l=b$. This analysis is often referred to as the entailment analysis of presupposition.

This solution would have been satisfactory if pragmatic theory had been up to the task assigned to it, and if, moreover, there had not been empirical obstacles. As regards the latter, it has been observed (Seuren 1985: 229-34) (a) that in certain constructions negation cannot cancel presuppositions but has to preserve them, and (b) that in other constructions the only negation possible is the presupposition-cancelling one. This calls for some illustration.

\subsection{Linguistic complications}

Although no claim of completeness can be made, and further cases will almost certainly come to light as research proceeds, we can say that in the following classes of cases negation is per se presupposition-preserving:

A. Morphologically incorporated negations (except when incorporated into a quantifier, as in nobody, never, neither). Thus, negative prefixes like un-, in-, dis-, a-, cannot fulfil the cancelling role of not as in (3) above. Thus, $(4 a)$ is strongly felt to be incompatible, whereas (4b) easily allows for the 
cancelling interpretation. The exclamation mark indicates incompatibility (i.e. contrariness):

a. !Tim is UNrealistic about the risk: he doesn't know there to be one.

b. $\sqrt{T}$ im is NOT realistic about the risk: he doesn't know there to be one.

B. Negations in non-canonical positions. By "canonical position" is meant, for negation in English at least, the position in construction with the finite verb form. The remarkable thing is that negations in any other position than the canonical one are necessarily presupposition-preserving, even when they are logically speaking the highest operator and thus function as sentence negation:

a. !NOT all doors were locked: there wére no doors.

b. $\sqrt{A}$ ll doors were NOT locked: there wére no doors.

Both sentences are to be understood with the negation as the highest operator, followed by the universal quantifier. (5a) poses no problem for classical logic: since the first sentence of (5a) entails the existence of doors, it is incompatible with the second sentence. But (5b), which should have the same analysis, does pose a problem, precisely because it is not a contrary pair. In our analysis, an account of the logical properties of presuppositions will put this right.

C. Negations in non-assertive clauses. Typically, negations in non-assertive subordinate or main clauses cannot cancel presuppositions:

(6) a. !Tim seems NOT to be back: he hasn't been away at all.

b. $\sqrt{T}$ im does NOT seem to be back: he hasn't been away at all.

!Do NOT go back to your wife: you haven't even left her.

D. Negations with certain quantifiers. As was demonstrated in (5b) above, the negation with the quantifier all can be used to cancel presuppositions. Not, however, it seems, with, e.g., each (of the), or both (of the):

!Each of the children was NOT given a sweet: there wére no children.

(9) !Both of his children are NOT spoiled: he hás no children. 
E. Non-extraposed factive subject clauses. Negation over a factive main verb does not affect the factive presupposition, though it may affect other presuppositions in the same sentence:

(10) a. !That Tom speaks French does NOT irritate Joanna: he doesn't speak French.

b. $\sqrt{\mathrm{It}}$ does NOT irritate Joanna that Tom speaks French: he doesn't.

Note, however, that the existential presupposition that goes with the object of a factive verb like irritate can easily be cancelled, even with a nonextraposed factive clause:

$\sqrt{T}$ hat Tom speaks French does NOT irritate the king of France: there is no King of France.

Note, moreover, that when the factive clause is pronominalized by means of that, the factive presupposition still has to remain under negation, as is shown in (12a). But when the negation is reinforced with epistemic possibility and comes out as cannot, the factive presupposition can be cancelled, as in $(12 b)$ :

a. !That does NOT irritate Joanna: he doesn't speak French. (cp (10a)).

b. $\sqrt{T}$ hat CANNOT irritate Joanna: he doesn't speak French.

F. Cleft and pseudocleft constructions. As is well-known, these have a specific existential presupposition associated with the clefted (i.e. the WH-) constituent: if in the non-cleft version of the sentence this constituent requires a really existing object for the sentence to be true, so does the clefted constituent, whether in cleft or in pseudo-cleft constructions. This presupposition is uncancellable by negation:

!What he said was NOT "Damn!": he said nothing at all.

But other presuppositions, not directly associated with the clefted constituent, are fully cancellable:

$\sqrt{\mathrm{It}}$ is NOT Mr. Hamilton who wrote the letter: Mr. Hamilton doesn't exist.

G. Contrastive accents. This is an exact parallel to the (pseudo)cleft constructions. In sentences with contrastive accent the accented constituent 
serves as a predicate establishing the identity of the entity mentioned in the non-accented part. This latter entity is presupposed to exist in all cases where it is in the corresponding sentence without contrastive accent. This presupposition cannot be cancelled under negation:

$$
\text { !The WAITER didn't start the argument: nobody did. }
$$

Again, however, other presuppositions, such as those associated with the accented part, are freely cancellable:

$$
\sqrt{T} \text { he WAITER did NOT start the argument: there was no waiter. }
$$

H. Negations with Negative Polarity Items. As is well-known, every language has a, usually large, number of so-called "Negative Polarity Items" (NPI). These are words, constructions or expressions which, for no known reason, require a negation or, for some at least, a negative word when used in simple declarative sentences. (Their behaviour in other clause-types differs in ways that have as yet never been systematically studied.) Some, but certainly not all, NPIs allow for emphatic auxiliaries (do-support when there is no auxiliary) as a form of negativity. In the examples below the NPIs are italicised. (17a) gives a standard case. In (17b, c) one has NPIs with negative words (hardly, difficult). In (17d) one has a case of emphatic dosupport:
a. She couldn't possibly have known that.
b. She could hardly breathe any more.
c. It was difficult for him to go on any longer. (cp. * ... easy...)
d. It DOES matter that her boss is an alcoholic.

The point is that the negation which is required in simple assertive clauses with NPIs (if there is no other negative word and no auxiliary emphasis) is per se presupposition-preserving, for all presuppositions in the sentence. Thus, the sentences of (18) are all strongly felt to be incompatible (contrary):
a. !It does NOT matter that her boss is an alcoholic: the man isn't. (factive)
b. !Mr Jones does NOT live in Paris any more: he doesn't exist. (ex- istential)
c. !He did NOT at all acknowledge my presence: I wasn't there. (factive)

Interestingly, NPIs have a counterpart in so-called "Positive Polarity 
Items"' (PPI). When a PPI stands directly under negation, the sentence loses its default property of inviting presuppositional inferences and acquires what is usually called an "echo effect": it sounds as if the same sentence but without the negation has been uttered (or strongly suggested) in immediately preceding discourse, preferably by a different speaker. Take, for example, the PPI still, which induces the presupposition that what is said in the rest of the sentence was true at least till just before the moment of utterance, and the sentence as a whole, if in the present tense, asserts that that situation continues to obtain. Contrast this with the NPI any more, which induces the same presupposition but lets the sentence, with the obligatory negation, assert that that situation has ceased to obtain. Thus, given a sentence with the PPI still, its natural negation will not be that sentence with the default-cancelling and "echoing" not but rather that sentence with still replaced by not ... any more, as in the following pair:

a. Harold still lives in Paris.

b. Harold doesn't live in Paris any more.

The test is now that the presuppositions of (19a) are no longer default inferences when simple not is inserted, whereas those of $(19 \mathrm{~b})$ are not cancellable, as we saw in (18b):

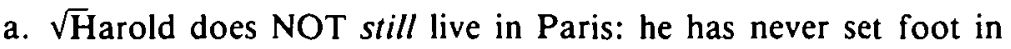
France.

b. !Harold doesn't live in Paris any more: he has never set foot in France.

Examples of English PPIs are (see also Seuren 1985: 233): rather, far from, hardly, terrific, daunting, ravenous, staunch, as fit as a fiddle, at most, at least, perhaps, already, certainly, surely, awful, even, each, both, most, some, several, few, not. (Note that the negation word not itself is a PPI: a succession of two or more nots has the effect of cancelling all presuppositions and creating an echo. But if there is no stark succession of two nots, as in (21) below, they can both be presupposition-preserving.)

Thus, generally, when a PPI stands in the immediate scope of not it cancels the presuppositions of the sentence, not leaving even a default inference. It then also produces an echo-effect. Baker has observed (1970) that, interestingly, this is not so when there is double negation (other than stark succession of nots):

There is nobody here who hasn't already had his breakfast.

Baker's observations are tantalizing, but still unexplained. 
A further unexplained complication is that some, not all, PPIs allow themselves to stand under an unaccented not when an explicit or implicit comparison is made.
a. You are not still building (as we are).
b. She hadn't already finished (as you had).

Such sentences have a (slight) echo-effect, but preserve presuppositions. However, and this is crucial to us, heavy accent on not is excluded for such cases.

PPIs are generally excluded in the scope of implicitly negative operators (or, if one prefers, operators with underlying negation), such as the comparative than. This is shown in (23a). In (23b) the some is outside the scope of than; this sentence is interpretable as "there are some of her colleagues who she is richer than":
a. *She is richer than you already/still are.

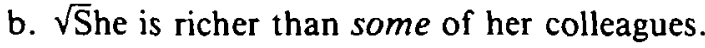

This agrees with the observation, made in A above, that morphologically incorporated negations are necessarily presupposition-preserving and cannot (pace Baker) take PPIs in their immediate scope.

It is not known what system or mechanism is responsible for the emergence of polarity items, whether positive or negative, and their behaviour. Nor is much known about the question what factors lie behind the fact that often the negation word cancels presuppositions as entailments but leaves them as default inferences, while in certain classes of cases it preserves some or all of the presuppositions in the sentence at hand, and in other classes of cases it eliminates even the default inference of the presuppositions. It would seem that a theory of topic-comment modulation (as being elaborated by Van Kuppevelt in Nijmegen) might lay bare the grounds of the necessary preservation of presuppositions in the categories $E, F$ and $G$ above (i.e. non-extraposed factive clauses, (pseudo)clefts and contrastive accents): Sentences that fall under these categories have a grammatically fixed topiccomment structure built into them in such a way that the topic coincides with the presupposition, and presupposition-cancelling can probably be shown to be incompatible with topic-hood. Yet on the whole, our theoretical insights still fall short of an explanation of the facts concerned.

Even so, however, the answer cannot be simply that the negation operator in language is just the simple bivalent truth-functional operator known from classical logic, somehow modified by pragmatic factors, as the entailment analysis has it. This type of analysis is in principle unable to cope with the clear-cut difference in entailment types between the cases where presup- 
positions are necessarily preserved and those where they are necessarily cancelled. The minimal conclusion to be drawn is that there are at least three systematically differing ways of using the negation: (1) with the presuppositions necessarily preserved, (2) with the presuppositions reduced to default inferences, and (3) with even the default inferences removed. The question is now: what theory has the best chance of coming to grips with the facts observed above? A Gricean pragmatic theory may be considered for certain peripheral parts of the job, but it does not seem the first choice for the central problems, given the known failure, so far, of such theories in those areas. The observed facts are anyway too linguistically structural to be a natural object for pragmatics, whose typical hunting ground is the nonlinguistic interactional aspects of communication.

\subsection{Theoretical alternatives}

\subsubsection{Argument-split theories}

As far as can be judged at present, there seem to be, in principle, two viable alternatives. First, one can try and keep negation classical and bivalent, as in the entailment analysis, but seek a, preferably non-pragmatic, solution for the problems raised. Such a solution would have to consist, not in the assumption of different negation operators, but in the assumption of different argument-values for one single negation operator. If this is the classical bivalent operator without gaps, one solution might be to show that there are good empirical grounds for assuming that under certain conditions the classical negation operator takes as argument a proposition of type $\alpha$, which leaves the presuppositions as default inferences, while under different conditions it takes as argument a proposition of type $\beta$, which necessarily preserves presuppositions, and under again different conditions it takes as argument a proposition of type $\gamma$, which has not even the default inferences left to it. Alternatively, one may assume that the one and only negation operator of natural language is the presupposition-preserving Strawsonian negation, which is bivalent but with gaps. In that case it must be shown that it pays to let this negation operate, under certain conditions, only on propositions of type $\beta$ (with presuppositions), and under other conditions only on propositions of type $\gamma$ (which have lost their presuppositions). If neither set of conditions is met, the sentence will be ambiguous between a presupposition-preserving and a presupposition-cancelling reading, and, some, perhaps pragmatic, theory will have to explain why the former is the preferred one and the latter is realized only under marked conditions. Let us call theories of this type argument-split (or $A S$ ) theories.

No such theory has been put on the market yet in anything like a sufficiently elaborated version. Even so, however, it must be said that there are 
as yet no decisive a priori grounds for ruling out theories of this kind. An obvious thought is to split up a sentence into a logical conjunction of its presuppositions and its assertion proper. The "argument split" would then amount to a simple difference in scope for the negation operator. Let $a_{p}$ stand for the sentence $a$ with its presuppositions $p$. "Not-a" would then, in formally unmarked cases at least, be ambiguous between $p \wedge \neg a$ on the one hand, and $\neg(p \wedge a)$ on the other, with, presumably, a preference for the former. This analysis (let us call it the conjunction analysis) is usually implicitly invoked when authors speak of "internal", i.e. presupposition-preserving, versus "external", i.e. presupposition-cancelling, negation. It has, however, little going for it, mainly because of structural reasons. One problem with this conjunction analysis is that the set of presuppositions $p$ functions structurally and logically simply as a conjunct or set of conjuncts. For this to be possible, $p$ has to be "unpacked" from the carrier sentence $a$ in the sense that $p$ must be fleshed out as a full, syntactically and semantically correct sentence or set of sentences. Since none of the existing theories of syntax or semantics is remotely capable of carrying out such a task, this analysis must, for grammatical reasons, be deemed to be unrealistic. A further problem for the conjunction analysis consists in the fact that it cannot explain why (24a) is felt to be contradictory whereas (24b) is not:

a. !There was a car. The car stopped, and the car did not stop.

b. There was a car, and the car stopped. And there was a car and the car did not stop.

If, as this theory would seem to require, every occurrence of a definite description brings along a spelling out of the associated existential presupposition, the only possible, contradictory reading of (24a) should be impossible, and the reading associated with (24b) would then be the only possible one. ${ }^{1}$

In work that is available but not yet published at the time of writing, Van der Sandt (to appear) proposes an AS-analysis with the classical bivalent negation operator. In this analysis, all sentences consist of a strictly propositional part plus an extra bag of additional information which contains the presuppositions, the (scalar) implicatures, and properties of style and register (more will be said about this in a moment). The negation operator standardly applies only to the strict proposition and will thus preserve the presuppositions as well as the other "extras". But it may also take as argument the strict proposition under an assumed "echo" operator which is not phonologically realized other than by special intonational features, and which ensures that the strict proposition plus its additional information are bundled together. In those cases the negation operator will extend not only over the implicatures and other non-truth-conditional inferences but also 
over the presuppositions, with the result that these are cancelled, and are no longer logical consequences. The echo operator is meant to account for all cases where a sentence functions as a correction on a previously uttered sentence. That is, the non-negated part of the first sentences of (25) are all considered to stand under the echo operator:

(25) a. It is NOT sad that she died so young: she is still very much alive.

b. He doesn't hate SOME of his pupils: he hates them ALL.

c. No Johnny, aunt Bessie isn't "SPLITTING" tomorrow, she is LEAVING.

In (25a), a factive presupposition is denied. In (25b), a scalar implicature is corrected. (25c) corrects an expression deemed inappropriate for stylistic or sociolinguistic reasons. (cp. Horn 1985 for an ample discussion). According to this analysis, ordinary classical negation will do, but there is a systematic ambiguity in the argument proposition depending on whether or not it stands under the echo operator. At least as far as presuppositions are concerned, this theory is logically equivalent with the conjunction analysis. Yet structurally it is different, in that the extra information need not be "unpacked" but is part of the semantics and pragmatics of the utterance that expresses the strict proposition. Moreover, such an analysis will not have to cope with problems such as (24) above, since neither (24a) nor (24b) satisfy the conditions for the use of the echo operator, and the theory would, if suitably extended, make the right predictions. This variety of AS-theory will, therefore, have a considerable edge over the conjunction analysis, though it still needs to be shown how, on account of what structural principles, utterances carry the semantic "extras". A split in predicate conditions, as in (30) below, may work for presuppositions, but how would one account for the implicatures and the style or register implications?

A central aspect of this analysis is the attempt to subsume all cases of utterance correction, i.e. all echo-cases, under one category, semantically characterized by the echo operator. Underlying this attempt is the claim that all negations that extend over presuppositions, (scalar) implicatures, or register choices, as exemplified in $(25 a-c)$ above, are utterance appropriateness denials (hence the echo), and form a natural class. It remains to be seen whether this claim will withstand scrutiny.

One specific difficulty for this theory lies in the fact that the negation that cancels presuppositions cannot occur in any other position in the sentence than what has been called the canonical position, i.e. with the finite verb form (see category B above: negations in non-canonical positions necessarily preserve presuppositions). In this respect the presupposition-cancelling negation distinguishes itself from negations in, let us say, the Horn cases, i.e. negations that cancel (scalar) implicatures or correct inappropriate lexi- 
cal, phonological or grammatical choices. Negations in Horn cases do not have to be in the canonical position, witness, e.g.:

a. Not several but all guests left after the row.

b. Not Lizzy, if you please, but Her Majesty the Queen was wearing a red hat (cp. Horn 1985:133).

In $(26 a, b)$ the negation precedes the surface subject, and is hence not in the canonical position. One notes, moreover, that the quantifier several, which is, as we have seen, a PPI, does not function as a PPI here, apparently because the word used is not several but its quoted counterpart "several". If it had been a PPI here, the negation would have had to occupy the canonical position, and would have been presupposition-cancelling. This difference is quite real, and considerably weakens the thesis that all cases of utterance correction form one "natural" class, which must, therefore, be accounted for uniformly. Note, for example, the difference between (27a), which is an acceptable case of presupposition-cancelling, and $(27 \mathrm{~b}, \mathrm{c})$, which are not, because of their being incompatible:

a. $\sqrt{\mathrm{H}}$ did NOT only lose his arm. He only lost his little finger.

b. !Not only did he lose his arm. He only lost his little finger.

c. !He not only lost his arm. He only lost his little finger.

A theory like Van der Sandt's, with the echo operator, will have to explain why $(27 b, c)$ do not work, while $(26 a, b)$ do.

This is not just a grammatical problem (though, if it were, it would be serious enough), it is also a semantic problem. For, contrary to what this theory predicts, the negation over the Horn cases does not cancel presuppositions. Take, for example, $(25 b, c)$ above, and try replacing the second sentence, i.e. the correction, by a presupposition denial. The result is unacceptable:

a. !He doesn't hate SOME of his pupils: he doesn't exist.

b. !No Johnny, aunt Bessie isn't "SPLITTING" tomorrow: there is no aunt Bessie.

It does not seem likely, therefore, that presupposition denials form one single natural class with the Horn cases, i.e. implicature denials and style or register corrections. On the contrary, it is quite thinkable that the Horn cases, as in $(25 \mathrm{~b}, \mathrm{c})$ above, are special instances of constrastive accent (or clefting), and will thus necessarily preserve presuppositions (cp. F and $G$ above). They will then require an analysis along something of the following lines (for (25b) and (25c), respectively): 
a. the proper word * in: "he hates * of his pupils" is not "some" but "all".

b. the proper word * in: "aunt Bessie is * tomorrow" is not "splitting" but "leaving".

The transformational rule of Predicate Lowering (Seuren 1985: 308-11) would then lower the predicates of $(29 a, b)$ onto the position marked by the asterisk, thus giving (25b) and (25c). Note that (25a) cannot be generated along these principles. In any case, since little is known, as yet, about the grammatical aspects of sentences containing quoted forms (the "grammar of quotes" still has to be written), we will let this particular topic rest, and proceed to a discussion of possible alternative theories.

\subsubsection{NEG-split theories}

The other class of possible theories is characterized by the assumption that it is not the argument of the negation which is somehow ambiguous, but the negation itself. Although this possibility is mentioned in virtually all publications on the issue, it is not often pursued in detail. Let us speak of the class of possible NEG-split theories. The main recent proponents of this approach, often with an admixture of AS, are Blau (1978), Karttunen \& Peters (1979), Horn (1985) and Seuren (1985). There is also Bochvar (1938), which is, however, too much lacking, understandably, in linguistic sophistication to be taken into serious account here. I shall discuss Karttunen \& Peters, Horn and my own proposal now, and Blau in section 2.2.

In the first of these, Kartiunen \& Peters (1979), the authors propose that language has two negations, one of which preserves, and one of which cancels conventional implicatures. As far as their logic is concerned, however, the difference lies only in the composition of the argument proposition, which is sometimes just the proposition, and sometimes the proposition plus its conventional implicatures. This is like the Russellian conjunction analysis if the presuppositions are replaced with conventional implicatures. Truth-functionally, therefore, there is only one negation, i.e. the classical operator, with some form of argument-split. The difference between their two negations lies in what they are meant to do with the implicatures. And here the analysis runs into trouble.

Karttunen \& Peters associate with each expression $X$ in the language a double translation, one being the extension or (e-)expression $(X)^{\mathrm{e}}$, and the other the implicature (or $i$-)expression $(X)^{\mathrm{i}}$. The e-expression takes the semantic value of $X$ as in standard formal semantics. The i-expression denotes the Gricean conventional implicatures, which, in Karttunen \& Peters' view, include at least most of the presuppositions. They distinguish two distinct negations, the ordinary negation not, which is presupposition- 
preserving, and the presupposition-cancelling contradictory negation NOT. If " $A_{P}$ " stands for " $A$ with the implicature(s) $P$ ", $\left(\text { not }-A_{p}\right)^{\mathrm{e}}$ (the eexpression) $=\neg A$, whiie the corresponding $\mathrm{i}$-expression $\left(\text { not }-A_{p}\right)^{\mathrm{i}}=\mathrm{P}$. Then, $\left(N O T-A_{p}\right)^{\mathrm{e}}=\neg(A \wedge P)$, and $\left(\text { NOT }-A_{p}\right)^{\mathrm{i}}=P \vee \neg P$. Thus, as far as the e-expressions go there is no difference with the conjunction analysis, except that the implicatures take the place of the presuppositions. So far, the negation operator is in no way different from the classical bivalent operator. Only the $\mathrm{i}$-expressions make a difference.

It must be appreciated that this analysis is an attempt at providing a solid basis for the pragmatic distinction that these authors propose underlies the different uses of negation. Yet it runs into trouble, as we will now see. The i-expression, for not- $A_{p}$ is, as we have seen, just $P$ (more precisely: $\left.(P)^{e}\right)$. That is, $A_{P}$ carries the set of conventional implicatures $P$, which remains outside the scope of ordinary not. Contradictory NOT, on the other hand, is neutral with respect to $P$, since the i-expression is the tautological $P \vee \neg$ $P$. Moreover, $P$ falls under the scope of NOT. Given that, in this analysis, $\left(A_{P} \text { or } B_{Q}\right)^{\mathrm{i}}=(P \vee B) \wedge(A \vee Q)$, it follows that $\left(\operatorname{NOT}\left(A_{P} \text { or } B_{Q}\right)\right)^{e}=\neg$ $((A \vee B) \wedge(P \vee B) \wedge(A \vee Q))$. Now let, e.g., $A$ be true and $P, B$ and $Q$ be false (which is possible because conventional implicatures are not necessarily entailed by their carrier sentences). Then $\left(A_{P} \text { or } B_{Q}\right)^{e}$ is true, given the truth of $(A)^{\mathrm{e}}$. But $\left(\operatorname{NOT}\left(A_{P} \text { or } B_{Q}\right)\right)^{\mathrm{e}}$ is also true, since $((A \vee B) \wedge(P$ $\vee B) \wedge(A \vee Q)$ ) is false, given the falsity of the second conjunct. Under this analysis, therefore, the basic Aristotelian Principle of Contradiction seems to be violated, with the result that the logic collapses. No attempts have been made, to my knowledge, to repair this.

Horn (1985) advocates a position which implies that "negation is indeed ambiguous, contra Atlas, Kempson, Gazdar, et al. But contra Russell, Karttunen \& Peters, and the three-valued logicians, it is not SEMANTICALLY ambiguous. Rather, we are dealing with a PRAGMATIC ambiguity, a built-in duality of use." (Horn 1985:132). In this important paper, which is rich in observations though perhaps a little indulgent on theory. Horn follows the course, also, as we have seen, taken by Van der Sandt, of subsuming all negated echo-cases under one category, which he calls metalinguistic negation: "I seek to encompass all these examples under the rubric of metalinguistic negation: they all involve the same extended use of negation as a way for speakers to announce their unwillingness to assert something in a given way, or to accept another's assertion of it in that way. Given the behavioral resemblances just cited, as well as the prevailing Occamist considerations, there is no obvious reason NOT to collapse the presuppositioncancelling negation ... with the negation attaching to conversational implicature ..., to pronunciation ..., to morphology or syntax ..., to register or speech level ..., and to perspective or point of view". (Horn 1985:135) This analysis clearly has much in common with Van der Sandt's 
analysis discussed above. The main difference is that Van der Sandt does not split up the negation operator, making it "pragmatically ambiguous", as Horn does, but, instead, splits up the argument proposition of the negation using the echo operator.

The notion of "pragmatic ambiguity" is relatively new in linguistic theory. Horn (1985:135) attributes it to Donnellan (1966). Although there is some unclarity as to what it stands for, it implies anyway the possible use of the expression in question in a non-truthconditional way. Horn comes closest to a definition on p. 136: "What I am claiming for negation, then, is a use distinction: it can be a descriptive truth-functional operator, taking a proposition $p$ into a proposition not-p, or a metalinguistic operator which can be glossed ' $I$ object to $u$ ', where $u$ is crucially a linguistic utterance rather than an abstract proposition." This implies that not is ambiguous between the classical truth-functional operator on the one hand and a speech act operator on the other. Leaving aside the question of whether speech act theory is pragmatics and not semantics, the tenability of Horn's position depends in part on his contention that the metalinguistic uses are not truthconditional (and hence not truth-functional).

Here, it would seem, there are problems. If Horn's metalinguistic negation is defined as "I object to $u$ ", where $u$ is any linguistic utterance, then this operator runs the risk of overgenerating possible uses of not. For example, take a situation where two speakers, A and B, discuss the quality of the treatment of mental patients in a particular hospital. Now speaker A says: "One flew over the cuckoo's nest", wistfully reminding B of that great movie and clearly implying a similarity between what is shown in the movie and what is done in the hospital under discussion. Speaker B, however, violently disagrees, and certainly wishes to "object to $u$ ". If Horn's characterization of the non-truth conditional metalinguistic negation operator is to be taken literally, B should be able to say: “One did NOT fly over the cuckoo's nest", thereby objecting to A's utterance. Clearly, however, he cannot. Interestingly, most or all languages do have conventionalized ways of objecting to utterances in cases like this. In English, for example, B might say: "The hell/my foot one flew over the cuckoo's nest". But the standard negation word not cannot be used.

Horn will, therefore, have to delimit the class of cases where his metalinguistic negation can be used. It is not clear, however, that this can be done in a non-arbitrary way, as long as this negation is kept non-truth conditional and thus purely pragmatic. Horn himself is somewhat vague on this issue. He rests his case largely on Grice's (1967) thesis that "either truth or assertability can be affected by negation", and that when assertability is at issue the use of negation is not truth-functional (1985:137). He then extends this latter, "pragmatic" use to non-linguistic performances. On p. 136 he presents the amusing example of a piano lesson: "Piano student plays passage 
in manner $\mu$. Teacher: 'It's not [plays passage in manner $\mu$ ] - It's [plays same passage in manner $\mu$ ']." " Horn then comments: "The teacher's use of not is clearly not assimilable to anything remotely resembling truthfunctional propositional negation." This, however, is open to doubt. Surely, the teacher is making an assertion about the proper way of playing the passage, which, he says, is not $\mu$ but $\mu^{\prime}$ (cp. (29) above). In general, to say that assertability is affected by negation can hardly be taken to amount to anything other than to say that a certain expression is not assertable, and there is nothing non-truthconditional or even non-truthfunctional about that use of the negation.

The picture that emerges is roughly this. As a sentence operator (i.e. with highest scope), not can be used only when an assertion is truth-functionally denied, though the denial (negation) may affect an assertion of proper lexical choice or any other kind of performance. The negation word not cannot be used in cases that are really pragmatic, i.e. cases where no assertion is made but an allusion is made or some other non-truth conditional effect is intended by the making of an utterance (for example, if I quote a line from Shakespeare only to let it be known how well-read I am). The language may have other (often not terribly polite) expressions to object to utterances pragmatically, but not does not seem to be one of them. If this analysis is in principle correct. Horn's metalinguistic negation is fully truth-functional, and there is no "pragmatic" ambiguity. If there is any ambiguity, it must be logico-semantic.

A specific difficulty arises for Horn's position with regard to the word true. On p. 125 he agrees with the "fleshing out" of (3) above (The king of France is NOT bald: there is no king of France!) as "It is not true that the king of France is bald". Horn notes (p. 146) that this is not always possible with metalinguistic negation. Thus, he rightly considers $I t$ is not true that the dog SHAT on the carpet - he DEFECATED on it, unacceptable. And he will probably say the same of a sentence like It isn't true that this wine is GOOD - it's EXCELLENT. (I would argue that this is one more indication that we do not have a "natural" class here.) In any case, the possibility of the periphrastic it is not true that in some cases would seem to speak against the thesis that such uses are non-truthconditional. In order to save himself from this predicament Horn follows Grice again in saying that true often does not mean "true" but "assertable". This is, in turn, justified by examples like It's not true that they had a baby and got married - they got married and had a baby, where it is said that the difference is not truthconditional. But this is begging the question of how adequate standard propositional calculus is for the expression of events in temporal succession. It clearly is not. Given "the prevailing Occamist considerations" invoked by Horn himself (p. 135), there does, therefore, not seem to be sufficient reason to cut up the word true in the way proposed by Grice and Horn, or 
indeed to open up a non-truthconditional domain for not. (We shall come back to this in Section 3, where it will be shown that in an incremental semantics the truth-conditional difference between $p$ and $q$ and $q$ and $p$ is naturally expressible.)

The strength of Horn's position depends also on the motivation for classifying, essentially, the three categories of utterance correction exemplified in $(25 a-c)$ above as one "natural" class. Here, too, there is room for doubt, given cases like those presented in (26) and (27). Apart from the difficulty pointed out above in connection with the word true, for this analysis to be viable it will have to be explained why the presupposition-cancelling negation has to stand in the canonical position of the sentence, as illustrated by the examples (5) and (27) above in connection with Van der Sandt's work, while the other metalinguistic negations, as in $(26 \mathrm{a}, \mathrm{b})$, also occur in other positions. Horn's analysis, like Van der Sandt's, has to cope with the nonuniform behaviour of not in the cases that are meant to form a natural class. Then, there is the serious problem why English, and with it all known languages, do not systematically distinguish between the two functions reserved for it. ${ }^{2}$ This is a problem that plagues all theories of ambiguous not.

In my theory, as presented in Seuren (1985), the negation word not is also considered ambiguous, at least as far as its logical properties are concerned. More precisely, in my analysis not is LOGICALLY, and hence TRUTHCONDITIONALLY, and hence SEMANTICALLY, ambiguous. Yet the ambiguity is not arbitrary. The two not s share the property of banning their argument clause from the world picture presented in the running discourse. As far as the logic is concerned, a distinction is made between a minimal negation, symbolised as " ", which preserves presuppositions, and a radical negation, written " $\simeq$ ", which cancels them. Corresponding to the two negations there are three truth-values: true (written: 1), minimally false (written: 2), and radically false (written: 3 ). A sentence is true just in case all its truth-conditions are fulfilled. It is minimally false when the presuppositional conditions are fulfilled, but not the assertion conditions. It is radically false when not even the presuppositional conditions are fulfilled.

The presuppositions are all derived from the lexical conditions associated with the highest predicate of the sentence. These are divided into so-called preconditions and satisfaction conditions. The preconditions generate the presuppositions and the satisfaction conditions generate the "ordinary" entailments. Generally, let an $n$-termed predicate (over entities) $\mathrm{P}^{\mathrm{n}}$ have the extension $\sigma\left(\mathrm{P}^{\mathrm{n}}\right)$, in any given "world" $\mathrm{W}$. Then $\sigma\left(\mathrm{P}^{\mathrm{n}}\right)$ is the set of all $n$ tuples $t$ of entities in $W$ such that $t$ fulfils, first, the preconditions of $P^{n}$ and, next, the satisfaction conditions of $\mathrm{P}^{\mathrm{n}}$. Formally expressed, this looks like the following: 
$\sigma\left(\mathrm{P}^{\mathrm{n}}\right)=\left\{\left\langle\mathrm{r}_{1}, \ldots, \mathrm{r}_{\mathrm{n}}\right\rangle: \ldots\right.$ (preconditions) $\ldots \mid \ldots$ (satisfaction conditions) $\ldots l$ (where " $r_{i}$ " stands for a term referent)

It is claimed in Seuren (1985) that all presuppositions are derived from lexical preconditions, even those that seem to be associated with, or induced by, grammatical constructions such as (pseudo)cleft, or phonological features such as contrastive accent. Clearly, to uphold this view non-trivial grammatical analyses are required. This analysis is thus heavily dependent on sound grammatical theory.

Of more direct interest here is the question of the logical properties of the two negations, and of the relation between the logic and the semantics of natural language negation. In Seuren (1985: 239) the following truth-table is given for the two negations, with the classical bivalent operator thrown in for good measure, though I would claim that this classical operator does not occur in natural language:

\begin{tabular}{l|l|l|l|}
$\mathrm{p}$ & $\sim \mathrm{p}$ & $\approx \mathrm{p}$ & $\neg \mathrm{p}$ \\
\hline 1 & 2 & 2 & 2 \\
2 & 1 & 2 & 1 \\
3 & 3 & 1 & 1 \\
\hline
\end{tabular}

Fig. 4: Truth-table for minimal, radical, and classical negation (Seuren 1985: 239).

It is stated, moreover, that any system $\mathbf{P}$ of propositional calculus defined by the truth-functional operators $\neg, \wedge, \vee$, with $\neg$ defined as false when its argument is true, and true otherwise, $\wedge$ as selecting any value $v>1$ over 1 , and $\vee$ as selecting 1 over any value $v>1$, is logically equivalent to the classical bivalent system, no matter how many truth-values $\mathbf{P}$ has. In other words, the number of truth-values is irrelevant for the classical calculus, although with the three operators as defined any truth-value other than "true" or "false" is otiose. On the other hand, any n-valued logic allows for $\mathrm{n}-1$ different specific negations, whereby the classical negation (i.e. $\neg$ ) is equivalent to the disjunction of the other negations. Thus, in the threevalued system proposed here, $\neg p \equiv(\sim p \vee \simeq p)$. See for details and proofs the Appendix to Seuren (1985) by A. Weijters.

In Seuren (1985), no account is taken of other cases of "marked" negation, such as those discussed by Horn (1985) and exemplified in (25) and (26) above. It is Horn's merit to have drawn attention to these cases. Yet, as has been made clear above, I am not convinced that the Horn cases form one (natural) category with the cases of presupposition denial. In my view, presupposition denials form a separate category, distinct from the Horn cases. These I take to involve a specific form of linguistic quotation in (pseu- 
do)cleft or contrastive accent constructions. They therefore involve the minimal, not the radical, negation.

Then, In (1985) I provide no clear analysis of the relation between the logical and semantic properties of negation on the one hand, and its incremental effect on the other. No clear account is given why negation can be said to be ambiguous and yet sufficiently unified for there to be one single negation word. As long as this form of ambiguity is not clearly analysed and argued for, this analysis is open to Gazdar's criticism also applicable to Horn's analysis: why, if negation is ambiguous, is there no language in the world, as far as we know, which disambiguates between the two senses? In Section 3 more will be said about this. But first we shall have a closer look at the logical and model-theoretic aspects of the issue.

\section{THE MODEL-THEORY OF THREE-VALUED CALCULI}

In this section we will investigate the logical and model-theoretic properties of the trivalent system proposed. This seems useful because surprisingly little work has been done in this area, perhaps due to a deeply rooted mistrust, in logical circles, with regard to such calculi. It is hoped that the straightforward simplicity of the model-theoretic aspects of three- (and multi-)valued calculi will help to take away this distrust or lack of interest. We will concentrate on the model-theory of the calculi. Note, however, that what we call "model-theory" must be distinguished clearly from what we call "semantics for natural language". Most brands of formal semantics for natural language are based on the assumption that linguistic semantics is a variety of the kind of model-theoretic semantics developed in logic around the middle of this century. This assumption is radically dismissed here. We speak of "model-theory" when referring to "semantic" methods developed in logic. "Semantics", for us, is the study of the cognitive and linguistic processes that occur when sentences are understood.

The incremental unity of negation, as opposed to its semantic and logical ambiguity, will be adumbrated in this section, but not made explicit until section 3 . We will first take a look at the standard model-theory of the classical bivalent calculus.

\subsection{Standard Boolean model-theory for bivalent propositional calculus}

Let us revert to fig. 1 above, which gives the classical valuation space for a language $L(a, b, c)$ with no entailment relations among the atomic sentences $a, b, c$. In the standard conception, a sentence $p$ is said to "express a proposition". Let us use the notation " $/ \mathrm{p} /$ " for the proposition expressed 
by $p . / \mathrm{p} /$ is, in the standard conception, a characteristic function from valuations to truth-values or, in other words, the set of valuations in which $p$ is true: $\left\{\mathrm{v}_{\mathrm{n}} \mid \mathrm{v}_{\mathrm{n}}(p)=1\right\}$.

Thus, in the system presented in fig. $1, / a /$ is the function $\mid\left\langle v_{1}, 1\right\rangle$, $\left.\left\langle v_{2}, 2\right\rangle,\left\langle v_{3}, 1\right\rangle,\left\langle v_{4}, 2\right\rangle,\left\langle v_{5}, 1\right\rangle,\left\langle v_{6}, 2\right\rangle,\left\langle v_{7}, 1\right\rangle\right)$, or, alternatively, the set $\left\{v_{1}, v_{3}, v_{5}, v_{7}\right\}$, and $a$ expresses this function, or this set. In other words, an interpretable sentence is associated with a set of valuations, or, if it is $n$ ways ambiguous, with $n$ sets of valuations, in the way sketched in fig. 5 for the non-ambiguous sentence $a$ :

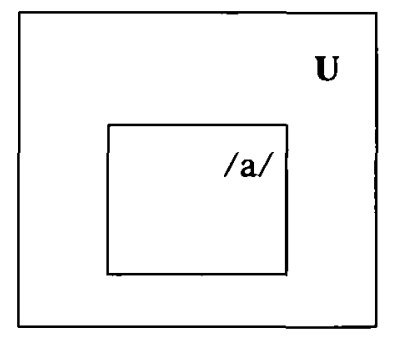

Fig. 5: /a/ as a subset of $\mathbf{U}$.

This has the advantage that the truth-functional operators can be interpreted as simple set-theoretic operations on the valuations in the field of valuations $\mathbf{U}$. The classical bivalent negation is now interpreted as follows: for any sentence $p, / \neg \mathrm{p} /=\mathrm{U}-/ \mathrm{p} /$, or, in other words, the complement of $/ \mathrm{p} /$ in $\mathbf{U}$. Thus, $/ \neg a /=\mathbf{U}-/ \mathrm{a} /=\left\{v_{2}, v_{4}, v_{6}, v_{8}\right\}$. Likewise for conjunction and disjunction: $/ p \wedge q /=/ p / \cap q /$, and $/ p \vee q /=/ p / U / q /$.

To say that $p$ is true in some $v_{n}$ now means: $v_{n} \in / p /$, and, of course, to say that $p$ is false in $v_{n}$ means: $v_{n} / p /$, which is equivalent to saying that $v_{n} \in U-/ p /$, or $\neg p$ is true in $v_{n}$. Again, to say that $\neg p$ is false in $v_{n}$ is: $v_{n}$ \& $-/ p /$, i.e., $v_{n} \in \mathbf{U}-(\mathrm{U}-/ \mathrm{p} /)$, and therefore $v_{n} \in / \mathrm{p} /$. On this basis we can give a general definition of the notion "truth-value", independently of the specific properties of the propositional calculus in question, as follows:

(31) In a propositional calculus $\mathbf{P}$ for a language $L$ in a universe (set of valuations) $\mathbf{U}$, there is a truth-value $\alpha$ just in case the propositions of the sentences of $L$ structure $\mathbf{U}$ in such a way that for every $p \epsilon$ $L$ and every $v_{n}$ in $\mathbf{U}$ there is precisely one set of valuations $\mathbf{H} \subseteq \mathbf{U}$ such that $v_{n}(p)=\alpha$ iff $v_{n} \in \mathbf{H}$.

Note that this definition allows for gaps in $\mathbf{U}$ only if a provision is introduced for a variable $U$. Take, for example, Fig. 2, where $a$ is unvalued in $v_{3}$ and $v_{6}$. Here, $/ a /=\left\{v_{1}, v_{4}\right\}$. Now the complement of $/ a /$ in $U$, i.e. $\mathrm{U}-/ \mathrm{a} /$, would be $\left\{\mathrm{v}_{2}, v_{3}, v_{5}, v_{6}\right\}$, and no gaps would be possible. We can, 
however, make a provision to let $U$ vary with each sentence $p \in L$ in such a way that $\mathbf{U}_{p}$ is precisely the set of valuations for which $p$ is valued, i.e. the intersection of all /q/ of $q \in L$ such that for all $\mathrm{v}_{\mathrm{n}} \in \mathrm{U}, \mathrm{v}_{\mathrm{n}} \in / \mathrm{q} /$ if $\mathrm{v}_{\mathrm{n}}(p)$ $=1$ or 2 . Then, for $a$ in fig. $2, \mathbf{U}_{\mathrm{a}}-/ \mathrm{a} /=\left(\mathrm{v}_{2}, \mathrm{v}_{\mathrm{s}}\right)$, and definition (31) will apply, with $\mathbf{U}$ relativised with respect to any given $p \in L$.

This gives the truth-table for negation in any $\mathbf{U}$ and any $L$ without gaps and with one single complement-taking negation, i.e. classical bivalent negation:

\begin{tabular}{|c|c|}
$p$ & $\neg p$ \\
\hline 1 & 2 \\
2 & 1 \\
\hline
\end{tabular}

Fig. 6: Truth-table for the classical bivalent negation

The truth-tables of the standard binary truth-functional operators $\wedge$ and $\vee$ are conveniently constructed as follows. Let $/ a /$ and $/ b /$ be represented as in fig. 7. The standard definition of $/ a \wedge b /$ is $/ a / \cap / b /$. Hence, any $v_{n} \epsilon$ $/ \mathrm{a} / \cap / \mathrm{b} /$ will yield the value " 1 " for $a \wedge b$, and all $v_{\mathrm{n}} \notin / \mathrm{a} / \cap / \mathrm{b} /$ will yield " 2 ".

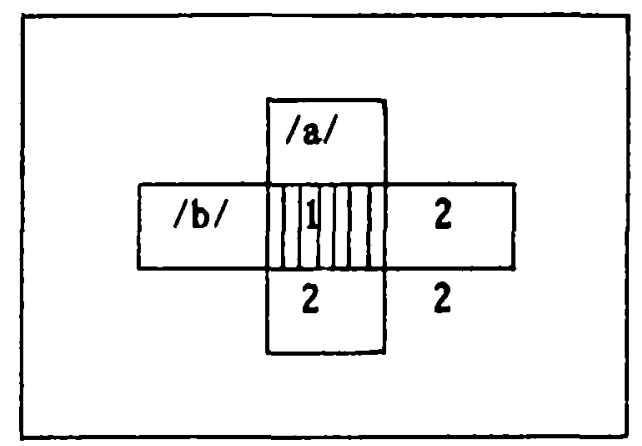

Fig. 7: Truth-table construction for classical $\wedge$.

Likewise for disjunction. Given that $/ \mathrm{a} \vee \mathrm{b} /=/ \mathrm{a} / \cup / \mathrm{b} /$, we have: 


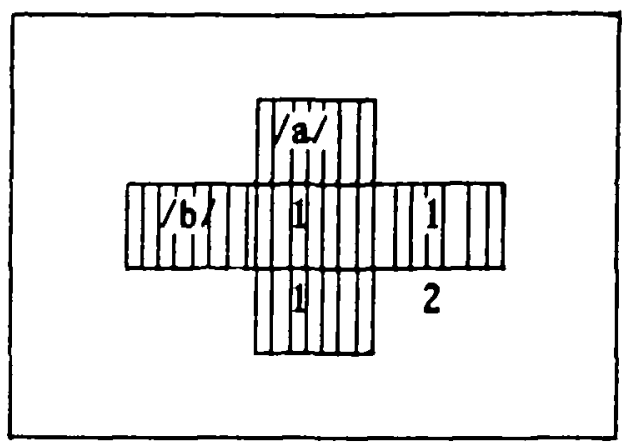

Fig. 8: Truth-table construction for classical $v$.

Since $a$ and $b$ are represented in figs. 7 and 8 as being logically independent, the tables thus constructed can be generalized to any $p, q \in L$.

\subsection{Presuppositional Boolean model-theory for trivalent propositional calculus}

We have seen (Section 1.2) that the Frege-Strawson analysis of presuppositional facts is untenable on empirical grounds: it is normally possible for a sentence to be true under negation even though its presuppositions are not all fulfilled. We have also seen (Sections $1.3 ; 1.4$ ), again on empirical grounds, that a reversal to standard bivalent logic is not a viable alternative. Our conclusion was that a choice had to be made between argument-split theories or NEG-split theories (or a combination of both). We will now have a look at the model-theoretic aspects of NEG-split theories.

Instead of restricting $\mathbf{U}$ for each sentence $p \in L$ to $\mathbf{U}_{p}$ and thus creating gaps, we will now keep $U$ constant again, avoiding gaps, but keep $U_{p}$ and re-interpret it as the subuniverse of $p$, still defined as the intersection of all $/ q /$ such that for all $v_{n} \in U, v_{n} \in / q /$ if $v_{n}(p)=1$ or 2 . $U_{p}$ is to be interpreted as the set of valuations ("possible worlds") in $\mathbf{U}$ expressed by the conjunction of all presuppositions of $p$. If $p$ has no presuppositions in the linguistic sense (as in, e.g., There are trees), we still let $p$ "presuppose" all logical truths, and say that, in such a case, $U_{p}=U$. (This, as we shall see in a moment, makes it impossible for a presuppositionless $p$ to be valued "3".)

Thus, for any sentence, $p, / \mathrm{p} / \subseteq \mathrm{U}_{\mathrm{p}} \subseteq \mathrm{U}$, as is demonstrated in fig. 9 for the sentence $a$, which we take to presuppose $b$ and not to have any further presuppositions. 


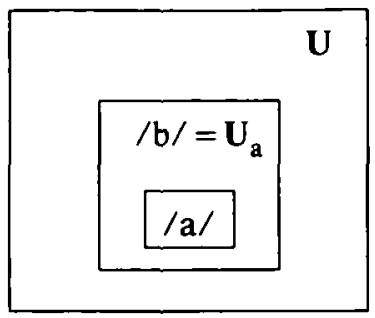

Fig. 9: /a/ as a subset of $\mathbf{U}_{\mathbf{a}}$, and $\mathbf{U}_{\mathbf{a}}$ as a subset of $\mathbf{U}$.

We have now created two disjoint complements for any $/ \mathrm{p} /$, besides the old classical complement, which is the union of the two others. We shall speak of:

the inner complement of $p: \mathbf{U}_{\mathrm{p}}-/ \mathrm{p} /$;

the outer complement of $p: \mathbf{U}-\mathbf{U}_{\mathrm{p}}$;

the total complement of $p: \mathrm{U}-/ \mathrm{p} /(=$ the classical complement of $p$ ).

For $L(a, b, c)$, with $a>>b$, and the valuation space as in fig. 2 above, this means that $/ a /=\left\{v_{1}, v_{4}\right\}, \mathbf{U}_{a}-/ a /=\left\{v_{2}, v_{5}\right\}, \mathbf{U}-\mathbf{U}_{a}=\left\{v_{3}, v_{6}\right\}$, and, of course, $U-/ a /=\left\{v_{2}, v_{3}, v_{5}, v_{6}\right\}$, or the union of the inner and the outer complements of $/ a /$.

The effect of this is more structure in $\mathbf{U}$, and, notably, the emergence of three truth-values, which we shall call "true" ("1"), "minimally false" ("2"), and "radically false" (" 3 "), defined as follows:

$$
\text { For any } v_{n} \text { in } \mathbf{U} \text { and any } p \in L: \begin{aligned}
v_{n}(p) & =1 \text { iff } \in / p / \\
v_{n}(p) & =2 \text { iff } v_{n} \in U_{p^{-}} / p / \\
v_{n}(p) & =3 \text { iff } v_{n} \in U-U_{p} .
\end{aligned}
$$

Clearly now, if $p$ has no presuppositions, and thus $\mathbf{U}_{\mathrm{p}}=\mathbf{U}, \mathrm{v}_{\mathrm{n}}(p)=3$ will be impossible because $v_{n} \in \mathbf{U} \cdot \mathbf{U}_{p}=\emptyset$ is impossible. Note also that there is no room left now for a fourth value corresponding to the total complement, since, given the definitions of the three values in (32), it is not true that for any $v_{n}$ and any $p \in L . v_{n}(p)=4$ iff $v_{n} \in U-/ p /$. (In fact, as the reader may care to ascertain, the assumption of such a fourth value will take away the truth-functionality of the truth-functional operators, and thus destroy the logic.)

This enables us to formulate the logical property of presuppositions:

If a sentence $p$ has the set $P_{p}$ as its presuppositions $\left.(p\rangle>P_{p}\right)$, then for all valuations $\mathrm{v}_{\mathrm{n}} \in \mathrm{U}, \mathrm{v}_{\mathrm{n}}(p)=3$ iff there is at least one $q \in P_{p}$ such that $v_{\mathrm{n}}(q) \neq 1$.

Equivalently, if $p$ ) $q$, then for all $v_{n} \in U$, if $v_{n}(p)=1$ or 2 than $v_{n}(q)=$ 1. It is important to realize, however, that the notion of presupposition 
plays no role in the logic proper once that has been set up. Everything in the logic will be done in terms of three truth-values and, as we will now see, the truth-functions, including the two negations. The point is that presuppositions is itself not a logical but a linguistic-semantic notion. The logic is only tailored to fit the presuppositional phenomena.

On the basis of this we now define two negation operators, the minimal negation $(\sim)$, and the radical negation $(\simeq)$, as follows:

$$
\text { For any } \begin{aligned}
p \in L: & \begin{aligned}
/ \sim \mathrm{p} / & =\mathbf{U}_{\mathrm{p}}-/ \mathrm{p} / \\
/ & \simeq \mathrm{p} /
\end{aligned}=\mathbf{U} \cdot \mathbf{U}_{\mathrm{p}}
\end{aligned}
$$

It now follows that if for some $v_{n}, v_{n}(p)=1$ and hence $v_{n} \in / p /$ or, equivalently, $v_{n} \in U_{p}-\left(U_{p}-/ p /\right), v_{n}(\sim p)=2$ (and vice versa), since $/ \sim p /$ $=\mathbf{U}_{\mathrm{p}}-\mathrm{p} /$, according to (34), and thus, according to $(32), \mathrm{v}_{\mathrm{n}}(\sim p)=2$. Likewise, it follows that if for some $v_{n}, v_{n}(p)=2$, and hence $v_{n} \in U_{p^{-}} / p /$, $v_{n}(\sim p)=1$ (and vice versa), according, again, to (32) and (34). This gives us part of the truth-table for minimal negation (cp. fig. 4), i.e. from 1 to 2 and vice versa. It does not give us yet the function value 3 from 3 . This we get when we realize that under the definitions given so far $\mathbf{U}_{p}=\mathbf{U}_{\sim p}$ for any $p$, since $U_{-p}$ is still the intersection of all /q/ such that for all $v_{n}$ $\epsilon U, v_{n} \in / q /$ if $v_{n}(p)=1$ or 2 . With this knowledge we can now say that if $v_{n}(p)=3$, and hence $v_{n} \in \mathbf{U}-\mathbf{U}_{p}$, or, equivalently, $v_{n} \in \mathbf{U}-\mathbf{U}_{-p}, v_{n}(\sim p)$ $=3$ (and vice versa), according to (32). This completes the construction of the truth-table for minimal negation, as given in fig. 4 above.

In similar fashion we derive the truth-table for radical negation. If, for some $v_{n}$ and for some $p, v_{n}(p)=1$, and thus $v_{n} \in / p /$ or, equivalently, $v_{n}$ $\in \mathbf{U}-(\mathbf{U}-/ \mathrm{p} /)$, then $v_{\mathrm{n}} \in \mathbf{U}-\left(\mathbf{U}-\mathbf{U}_{\mathrm{p}}\right)$, since $/ \mathrm{p} / \subseteq \mathbf{U}_{\mathrm{p}}$. Now, $\mathbf{U}=\mathbf{U}_{x \mathbf{p}}$, since $\simeq p$ can have no presuppositions in the linguistic sense. Therefore, $v_{n}(\simeq p)$ $=3$ is impossible, as we have seen. (Since $U_{\simeq p}$ is the intersection of all $/ q$ / such that for all $v_{n} \in U, v_{n} \in / q /$ if $v_{n}(\simeq p)=1$ or 2 , it follows that all $v_{n}$ $\epsilon \mathbf{U}$ must be a member of any $q$ intersecting with $U_{\simeq p}$, i.e. only logical truths can intersect to form $\mathbf{U}_{x p}$, and again, $\left.\mathbf{U}_{x p}=\mathbf{U}\right)$. This means that if $v_{n}(p)=1, v_{n} \in U_{x p}-\left(U-U_{p}\right)$. According to (34), $U-U_{p}=/ \approx p /$. Hence, if $v_{n}(p)=1, v_{n} \in \mathbf{U}_{\approx p}-/ \simeq p /$, which, according to (32), amounts to saying that $v_{n}(=p)=2$. Likewise, if $v_{n}(p)=2, v_{n} \in U_{p}-/ p /$, and hence $v_{n} \in U_{p}$, or, equivalently, $v_{n} \in \mathbf{U}-\left(\mathbf{U}-\mathbf{U}_{p}\right)$, and thus $v_{n} \in U_{x p}-\left(U-U_{p}\right)$, so that if $v_{n}(p)$ $=2, \mathrm{v}_{\mathrm{n}}(\simeq p)=2$. (It also follows that if $\mathrm{v}_{\mathrm{n}}(\simeq p)=2, \mathrm{v}_{\mathrm{n}}(p)=1$ or 2.) If, on the other hand, $v_{n}(p)=3$, then, by (31), $v_{n} \in U \cdot U_{p}$, and thus, according to $(34), v_{n} \in /=p /$, and hence $v_{n}(\simeq p)=1$, and vice versa. This establishes the truth-table for radical negation as given in fig. 4 above.

As regards the binary truth-functional operators, in particular conjunction and disjunction, it is quite possible to provide Boolean underpinnings for their truth-tables in a three-valued calculus constrained by minimal and 
radical negation. This can be done in a variety of ways, all of which will preserve their classical bivalent properties. For conjunction this means that, anyway, $/ \mathrm{p} \wedge \mathrm{q} /=/ \mathrm{p} / \cap / \mathrm{q} /$, as in the bivalent logic. The question is now how to define $\mathbf{U}_{\mathrm{p} \wedge \mathrm{q}}$ in such a way that justice is done to the logical property of presuppositions as defined in (33) above. One way is to define it as $U_{p} \cap$ $\mathbf{U}_{\mathrm{q}}$. The resulting truth-table, which is the table given in Seuren (1985: 239), is constructed in fig. 10, based on arbitrary, logically independent $a$ and $b$ :

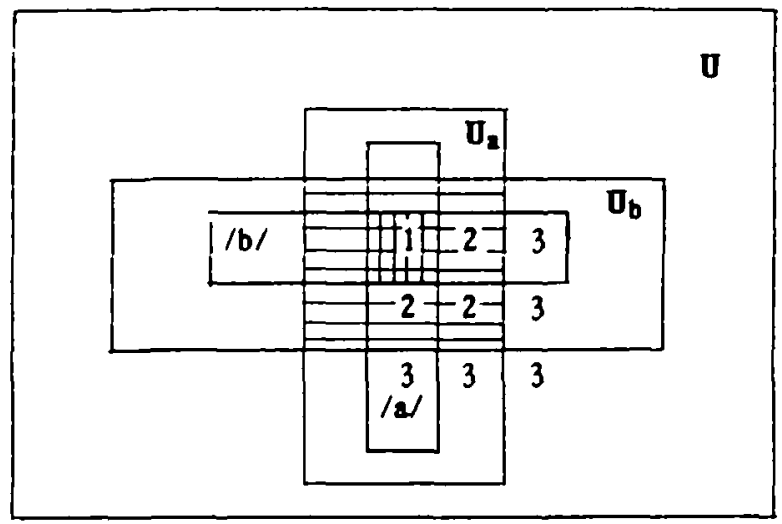

Fig. 10: Truth-table construction for trivalent $\wedge$ with $\mathbf{U}_{\mathbf{a} \wedge \mathrm{b}}=\mathrm{U}_{\mathrm{a}} \cap \mathrm{U}_{\mathrm{b}}$.

It is also possible, however, to define $\mathbf{U}_{\mathrm{p} \wedge \mathrm{q}}$ as $\mathbf{U}_{\mathrm{p}} \cup \mathbf{U}_{\mathrm{q}}$. This results in the table constructed in fig. 11:

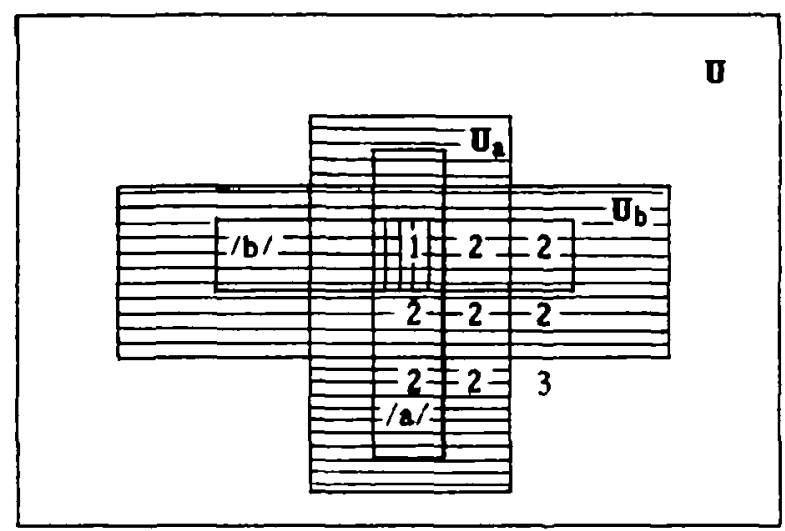

Fig. 11: Truth-table construction for trivalent $\wedge$ with $\mathbf{U}_{\mathbf{a} \wedge \mathrm{b}}=\mathbf{U}_{\mathbf{a}} \cup \mathbf{U}_{\mathrm{b}}$.

For disjunction a similar distinction does not work. We can define $\mathbf{U}_{\mathrm{pvq}}$ as $U_{p} \cup U_{q}$, which gives the truth-table presented in Seuren (1985:239), and constructed in fig. 12. But if $\mathbf{U}_{\mathrm{pvq}}$ is defined as $\mathbf{U}_{\mathrm{p}} \cap \mathbf{U}_{\mathrm{q}}$, as in fig. 13, no coherent interpretation results since, given the definitions in (32), a disjunction will be defined as both true and radically false when one disjunct is true 


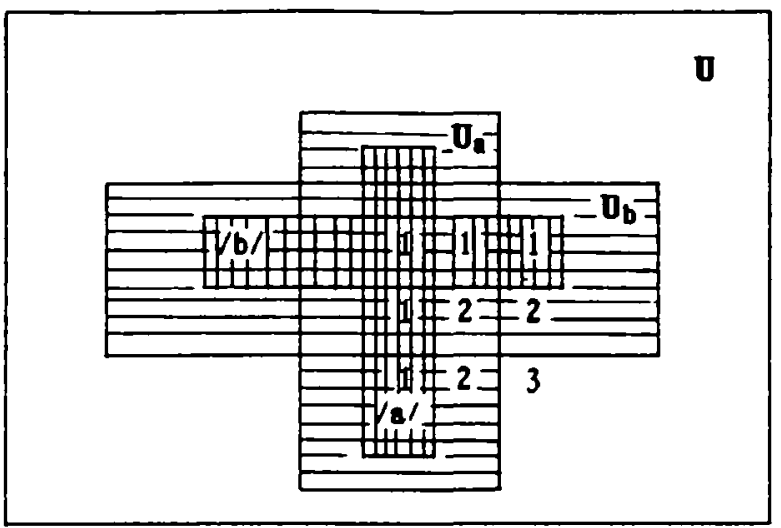

Fig. 12: Truth-table construction for trivalent $\wedge$ with $\mathbf{U}_{a v b}=\mathbf{U}_{\mathbf{a}} \cup \mathbf{U}_{b}$.

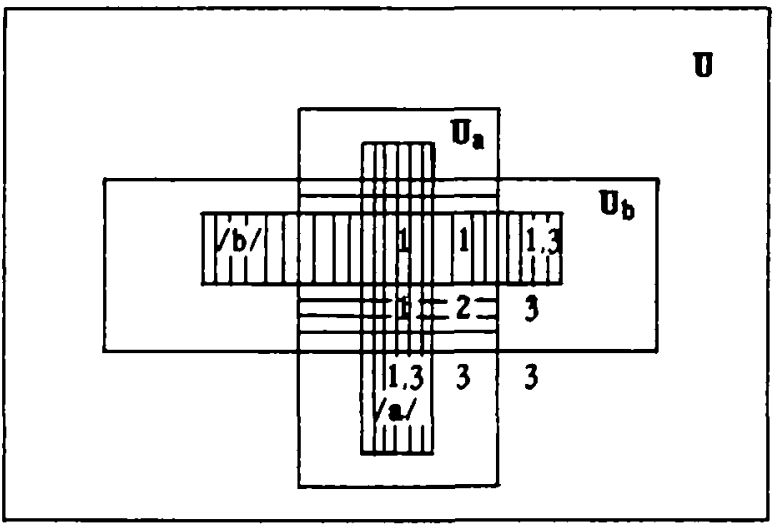

Fig. 13: Truth-table construction for trivalent $\vee$ with $\mathbf{U}_{a v b}=U_{a} \cap U_{b}$.

and the other radically false. Fig. 13, therefore, does not represent a possible analysis.

In Seuren (1985) the table for conjunction corresponds to fig. 10, as has been said. We now see that this table is preferable to the one constructed in fig. 11. According to fig. 10, a sentence of the form $a_{c} \wedge b_{d}$ (i.e. $a$ presupposing $c$, and $b$ presupposing $d$ ) generally presupposes both $c$ and $d$, since for any $v_{n} \in / a \wedge b /, v_{n} \in U_{a}$ and $v_{n} \in U_{b}$. In a general way, this is correct, since a sentence like:

Angus feeds his horse and Paddy feeds his donkey.

presupposes both that Angus has a horse and that Paddy has a donkey. The table constructed in fig. 11 does the same, but it also makes (35) presuppose that Angus has a horse or that Paddy has a donkey, which is linguistically incorrect, as appears from the infelicity of a discourse like (see Section 3 below): 
! Angus has a horse or Paddy has a donkey, and Angus feeds his horse and Paddy feeds his donkey.

We will see below, anyway, that it is not useful to let conjunctions carry presuppositions at all. $A n d$ must be taken to block any projection of presuppositions, because, if not, a sentence of the form $b$ and $a_{b}$ will both assert and presuppose $b$, which is rightly considered repugnant in all of the relevant literature. So it really does not matter much whether we take fig. 10 or fig. 11 as representing the correct table. Both preserve classical logic equally.

As regards disjunction. Seuren (1985: 239) gives the table represented in fig. 12. Thus defined, $\left.a_{c} \vee b_{d} \gg\right) c \vee d$, but $a_{c} \vee b_{d}$ does not presuppose either $c$ or $d$ singly, because for some $v_{n} \in / a \vee b /, v_{n} \notin U_{a}$ or $v_{n} \notin U_{b}$. Moreover, in fig. 12 a disjunction preserves all presuppositions that are shared by both disjuncts, or: $a_{c} \vee b_{c} \gg \mathrm{c}$. That this is so easily seen when one realizes that if $a$ ) $c$. $\mathbf{U}_{\mathrm{a}}$ cannot be larger than $/ \mathrm{c} /$ but it may be smaller. Likewise for $\mathbf{U}_{\mathrm{b}}$ if $b$ ) $>c$. Clearly, then, for any $v_{\mathrm{n}} \in / \mathrm{a} \vee \mathrm{b} /, \mathrm{v}_{\mathrm{n}}$ $\in \mathbf{U}_{\mathrm{a}} \cup \mathbf{U}_{\mathrm{b}}$, and hence, $\mathrm{v}_{\mathrm{n}} \in / \mathrm{c} /$. This is intuitively correct, witness the felicity of:

Angus has a horse, and he either feeds it or he starves it.

Fig. 12 thus seems to be the empirically correct.

Blau (1978:75) has trivalent truth-tables for both the presuppositionpreserving and the presupposition-cancelling negation. The former is identical to our $\sim$, the latter, however, is the classical negation $\neg$, i.e with truth converted into falsity, and all other values converted into truth. We have seen that this negation does not define a truth-value in any logic with more than two truth-values, since, given the minimal negation and its concomitant inner complement, the classical negation, with its total complement, no longer satisfies definition (31). Once an inner complement is defined, the only other negation that defines a truth-value is the one associated with the outer complement, i.e. the radical negation. In other words, in any system with more than two truth-values and more than one negation, the classical negation is dysfunctional as a separate operator.

Blau's trivalent conjunction and disjunction operators are defined (1978: 87) as follows: 


\begin{tabular}{|c|ccc|ccc|}
\cline { 2 - 6 } \multicolumn{1}{c|}{} & \multicolumn{3}{c|}{$\wedge q$} & \multicolumn{3}{c|}{$v q$} \\
$p$ & 1 & 2 & 3 & 1 & 2 & 3 \\
\hline 1 & 1 & 2 & 3 & 1 & 1 & 1 \\
2 & 2 & 2 & 2 & 1 & 2 & 3 \\
3 & 3 & 2 & 3 & 1 & 3 & 3 \\
\hline
\end{tabular}

Fig. 14: Truth-tables for trivalent conjunction and disjunction as in Blau (1978: 87).

The conjunction operator thus defined is inconsistent with Boolean semantics. This table is generated by $\mathbf{U}_{\mathrm{a} \wedge \mathrm{b}}=\mathbf{U}_{\mathrm{a}} \cup \mathbf{U}_{\mathrm{b}}$ (i.e. as in fig. 11), except that the combination of truth and radical falsity yields radical falsity, which fits into an analysis as in fig. 10 , with $\mathbf{U}_{\mathrm{a} \wedge \mathrm{b}}=\mathbf{U}_{\mathrm{a}} \cap \mathbf{U}_{\mathrm{b}}$. It should, in the conception of fig. 11 , yield minimal falsity for the combination of truth and radical falsity, since any valuation which has this combination of values will be a member of $U_{a} \cup U_{b}$. Blau's disjunction operator conforms to fig. 13, which, as we have seen, is incoherent in a model-theoretic (Boolean) interpretation. Blau's truth-tables for conjunction and disjunction must thus be rejected on grounds of model-theoretic interpretability.

We will see in a moment (Section 3) that the logical presuppositional properties of the conjunction operator do not matter at all for natural language semantics, since, as has already been said, presuppositions do not project through and, this being nothing but a concatenator of subsequent discourse increments. The logical properties of presupposition can only be taken to be epiphenomenal upon an underlying cognitive interpretative mechanism. The language is free to decide when presuppositions appear, these being a semantic property. However, before going into questions of this nature we will have a look at an alternative way of setting up the modeltheory of a propositional language.

\subsection{Constructive model-theory for bivalent non-presuppositional languages}

We have seen (Section 2.1) that the standard way of setting up a modeltheory for propositional languages is by associating each sentence of the language with the set of valuations, or, in a different terminology, possible worlds, in which it is true. That set is said to be the "proposition" expressed by that sentence. There is, however, another way of constructing the modeltheory. Take again the classical valuation space for $L(a, b, c)$ as represented in fig. 1 , which is repeated here for convenience: 


\begin{tabular}{|l|l|l|l|l|l|l|l|l}
$U$ & $a$ & $b$ & $c$ & $\neg a$ & $\neg b$ & $\neg c$ & $a \wedge b$ & $\ldots$ etc \\
\hline $\mathrm{v}_{1}:$ & 1 & 1 & 1 & 2 & 2 & 2 & 1 & \\
$\mathrm{v}_{2}:$ & 2 & 1 & 1 & 1 & 2 & 2 & 2 & \\
$\mathrm{v}_{3}:$ & 1 & 2 & 1 & 2 & 1 & 2 & 2 & \\
$\mathrm{v}_{4}:$ & 2 & 2 & 1 & 1 & 1 & 2 & 2 & \\
$\mathrm{v}_{5}:$ & 1 & 1 & 2 & 2 & 2 & 1 & 1 & \\
$\mathrm{v}_{6}:$ & 2 & 1 & 2 & 1 & 2 & 1 & 2 & \\
$\mathrm{v}_{7}:$ & 1 & 2 & 2 & 2 & 1 & 1 & 2 & \\
$\mathrm{v}_{8}:$ & 2 & 2 & 2 & 1 & 1 & 1 & 2 &
\end{tabular}

Fig. 1: Classical valuation space for $L(a, b, c)$.

Now, instead of letting a sentence express its proposition, which is a set of valuations, we go the other way around. We drop the notion of proposition as defined in standard model-theory, and consider a valuation $v_{n}$ to be a function from sentences of $L$ to truth-values, that is, as the set of sentences of $L$ for which $\mathrm{v}_{\mathrm{n}}$ has the value 1 . Thus, e.g., $\mathrm{v}_{2}=\{b, c, \neg a, \ldots)$ in fig. 1. It is easily seen that for a language $L$ all of whose sentences are atomic and logically independent, $\mathrm{U}=\boldsymbol{P}(L)$. Now to say that a sentence $p$, whether atomic or complex, is true in $v_{n}$, or: $v_{n}(p)=1$, is equivalent to saying that $p \in \mathrm{v}_{\mathrm{n}}$, and $\mathrm{v}_{\mathrm{n}}(p)=2$ means: $p \in L-\mathrm{v}_{\mathrm{n}}$. Valuations consisting of the atomic sentences of $L$ are automatically expanded by the truth-functional compositions of these sentences.

Now, having defined the truth-values, in the way indicated above, as:

$$
\begin{array}{r}
\text { For any } v_{n} \in U \text { and any } p \in L, v_{n}(p)=1 \text { iff } p \in v_{n}, \\
\text { and: } v_{n}(p)=2 \text { iff } p \in L-v_{n},
\end{array}
$$

and defining, in addition, the classical negation operator as follows:

$$
p \in \mathrm{v}_{\mathrm{n}} \text { iff } \neg p \in L-\mathrm{v}_{\mathrm{n}} \text {, and hence } p \in L-\mathrm{v}_{\mathrm{n}} \text { iff } \neg p \in \mathrm{v}_{\mathrm{n}} \text {, }
$$

we can establish the classical truth-table for $\neg$ in the following way:

$$
\begin{array}{lll}
\mathrm{v}_{\mathrm{n}}(\neg p)=1 \text { iff } \neg p \in \mathrm{v}_{\mathrm{n}} & \text { iff } p \in L-v_{n} & \text { iff } \mathrm{v}_{\mathrm{n}}(p)=2 \\
\mathrm{v}_{\mathrm{n}}(\neg p)=2 \text { iff } \neg p \in L-\mathrm{v}_{\mathrm{n}} & \text { iff } p \in \mathrm{v}_{\mathrm{n}} & \text { iff } \mathrm{v}_{\mathrm{n}}(p)=1 .
\end{array}
$$

In similar fashion we can, trivially, establish the truth-tables for $\wedge$ and $\checkmark$, given the following definitions:

(41) For any $v_{\mathrm{n}} \in \mathbf{U}$ and any $p, q \in L, p \wedge q \in \mathrm{v}_{\mathrm{n}}$ iff $p \in \mathrm{v}_{\mathrm{n}}$ and $q \in \mathrm{v}_{\mathrm{n}}$, and: $p \vee q \in \mathrm{v}_{\mathrm{n}}$ iff $p \in \mathrm{v}_{\mathrm{n}}$ or $q \in \mathrm{v}_{\mathrm{n}}$. 
This in itself is not very interesting, and there is no reason to prefer this treatment to the standard Boolean way of presenting the model-theory of propositional calculi, as long as one stays within the realm of mathematical logic. From a non-mathematical, linguistic point of view, however, a model-theoretic perspective in which valuations are defined as sets of sentences has definite advantages. These begin to show when one realizes that this perspective enables one to construct a valuation $v_{n}$ by taking the atomic sentences of $L$ one by one and deciding whether or not they are to be members of $v_{n}$. Whenever a sentence $p$ is not in $v_{n}$, then, obviously, it is in $L-v_{n}$, that is, then $\neg p \in \mathrm{v}_{\mathrm{n}}$, as we have seen. This property is relevant for the study of language, since it mirrors what speakers do when they build up a discourse domain: adding sentences to a discourse domain $\mathrm{D}$ can be seen as building up a valuation. The analog in Boolean model-theory is to construct the set of worlds that makes up a proposition. That perspective, however, does not seem to be useful in the understanding of linguistic processes (though, as long as we know as little as we do, we must remain careful in making such statements).

We shall call the perspective adopted here, in which valuations are defined as sets of sentences, constructive model-theory. In Section 3 we shall see how constructive model-theory can be put to use in a more fully fledged linguistic discourse semantics. First, however, we will have a look at the construction and definition of minimal and radical negation in this perspective.

\subsection{Constructive model-theory for trivalent propositional languages}

\subsubsection{Fully constructed valuations}

Still assuming fully constructed valuations (i.e. with values for all sentences of $L$ ), we must again, as in the Boolean case, construct two disjoint complements, each to be designated by a separate negation operator, in such a way that the logical property of presuppositions is expressed. To this end we need to define, for each valuation $v_{n}$, the presuppositional sublanguage for $v_{n}$, or $L_{\mathrm{v} n}$. Intuitively, $L_{\mathrm{v} n}$ is $L$ minus those sentences of $L$ that cannot be valued " 1 " or " 2 " on account of one or more of their presuppositions not being valued " 1 ". To express this formally, we first define the notion of presuppositional sublanguage for $q$, or $P L_{q}$, where $q$ is any sentence of $L$, in the following way:

(42) For any $q \in L, P L_{q}$ is the set of sentences $p \in L$ such that for all $v_{\mathrm{n}} \in U$, if $v_{n}(q) \neq 1$ then $v_{n}(p) \neq 1$ or 2 .

The next step is to define the notion of nonlanguage for $v_{n}$, or $N L_{\mathrm{vn}}$ : 
(43) For any $\mathrm{v}_{\mathrm{n}} \in \mathrm{U}, N L_{\mathrm{vn}}$ is the union of all $P L_{q}$ of $q \in L$ such that $\mathrm{v}_{\mathrm{n}}(q)$ $\neq 1$.

This enables us to define the presuppositional sublanguage, or $L_{v n}$, for any $v_{n} \in U$ as follows:

$$
\text { For any } v_{\mathrm{n}} \in \mathbf{U}, L_{v n}=L-N L_{\mathrm{vn}} \text {. }
$$

Now we can define three truth-values in the following way:

$$
\text { For any } v_{\mathrm{n}} \in \mathbf{U} \text { and any } p \in L, \quad \begin{aligned}
& v_{n}(p)=1 \text { iff } p \in v_{\mathrm{n}} \\
& \mathrm{v}_{\mathrm{n}}(p)=2 \text { iff } p \in L_{\mathrm{vn}}-v_{\mathrm{n}} \\
& \mathrm{v}_{\mathrm{n}}(p)=3 \text { iff } p \in L-L_{\mathrm{vn}} .
\end{aligned}
$$

The minimal and radical negations now allow for the following definitions:

$$
\text { For any } \begin{aligned}
& p \in L,-p \in \mathrm{v}_{\mathrm{n}} \text { iff } p \in L_{\mathrm{vn}}-\mathrm{v}_{\mathrm{n}}, \text { and }-p \in L_{\mathrm{vn}}-\mathrm{v}_{\mathrm{n}} \text { iff } \\
& p \in \mathrm{v}_{\mathrm{n}}
\end{aligned}
$$

Every $v_{n} \in \mathbf{U}$ thus has two complements, the inner complement or $L_{\mathrm{vn}}-\mathrm{v}_{\mathrm{n}}$, and the outer complement or $L-L_{\mathrm{vn}}$, - besides, of course, the total complement, which is the union of the previous two. The inner complement is designated by the minimal negation - (i.e., all $p \in L_{\mathrm{vn}}-\mathrm{v}_{\mathrm{n}}$ are made true by the prefixing of $\sim$ ), whereas the outer complement is designated by the radical negation $\simeq$ (all $p \in L-L_{\mathrm{vn}}$ are made true by $\simeq$ ), as is demonstrated in fig. 15:

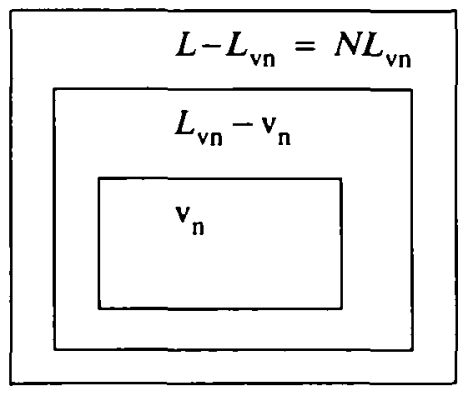

Fig. 15: Valuation $v_{n}$ with the inner complement $L_{v n}-v_{n}$ and the outer complement $L-L_{\mathrm{vn}}$

An important aspect of this, which will be further elaborated below, is the fact that both negation operators have in common the banishment of their argument sentence from the $v_{n}$ in question. The minimal negation 
"ejects" the argument sentence only into the inner complement of $v_{n}$, whereas the radical negation rockets it all the way into the outer complement, on account of its being incongruous with one or more other sentences that are members of $v_{n}$. Looked at from this angle, the two negations share the discourse-semantic property of banning their argument sentence from the valuation at hand, the difference being mainly one of intensity. Yet what is a difference in intensity has direct logical and truth-conditional consequences. The situation is comparable to that of a word like theft. In English law before 1967, theft was either a simple misdemeanour, to be tried in a minor court, or a serious felony, involving a heavier form of trial. In either case, however, the basis for prosecution was the same. In such a system there are thus two distinct forms of theft, yet they break the same rules of the penal code. Analogously, language has two forms of negation, but both involve a removal from the discourse representation. We shall come back to this later.

We are now, anyway, in a position to construct the truth-tables for minimal and radical negation. By definitions (45) and (46), $v_{\mathrm{n}}(\sim p)=1$ iff $\sim p \in \mathrm{v}_{\mathrm{n}}$ iff $p \in L_{\mathrm{vn}}-\mathrm{v}_{\mathrm{n}}$ iff $\mathrm{v}_{\mathrm{n}}(p)=2$. Then, $\mathrm{v}_{\mathrm{n}}(\sim p)=2$ iff $\sim p \in L_{\mathrm{vn}}-\mathrm{v}_{\mathrm{n}}$ iff $p \in \mathrm{v}_{\mathrm{n}}$ iff $\mathrm{v}_{\mathrm{n}}(p)=1$. From this it follows that $p \in L_{\mathrm{vn}}$ iff $\sim p \in L_{\mathrm{vn}}$. Hence, $p \in L-L_{\mathrm{vn}}$, iff $\sim p \in L-L_{\mathrm{vn}}$, so that, by (45), $\mathrm{v}_{\mathrm{n}}(p)=3$ iff $\mathrm{v}_{\mathrm{n}}(\sim$ $p)=3$. This gives the truth-table for the minimal negation.

For the radical negation we proceed likewise. $v_{n}(\simeq p)=1$ iff $\simeq p \in v_{n}$ iff $p \in L-L_{\mathrm{vn}}$, iff $\mathrm{v}_{\mathrm{n}}(p)=3$. We are, as we have seen, setting up the logic in such a way that a sentence under the radical negation operator has no linguistic presuppositions, since what this operator does is precisely cancel the linguistic presuppositions of its argument sentence. For the logic this means that any sentence, even one without linguistic presuppositions, still "presupposes" all logical truths, since whenever a presuppositionless sentence has the value " 1 " or " 2 ", the logical truths will still be valued "1". Given the definitions (42-44), it follows that, for any $v_{n}$ and for any $p, \simeq p \in$ $L_{\mathrm{vn}}$. This is so because if a sentence $r$ has no presuppositions, then at any $\mathrm{v}_{\mathrm{n}}$ there is no $q$ such that $\mathrm{v}_{\mathrm{n}}(q) \neq 1$ and, for all $\mathrm{v}_{\mathrm{m}} \in \mathrm{U}$, if $\mathrm{v}_{\mathrm{m}}(q) \neq 1$ then $v_{m}(r) \neq 1$ or 2 . Hence $r$ cannot be a sentence in any $P L_{q}$ of any $q \in L$, and can thus not be a sentence in any $N L_{\mathrm{vn}}$. Therefore, $r$ must, at any $\mathrm{v}_{\mathrm{n}}$, be a sentence of $L-N L_{\mathrm{vn}}$, and hence of $L_{\mathrm{v} n}$. This being so, we conclude that any sentence of the form $\simeq p$ can, at any $v_{n}$, only be either a sentence of $v_{\mathrm{n}}$ or of $L_{\mathrm{vn}}-v_{\mathrm{n}}$. (46) tells us that $=p \in \mathrm{v}_{\mathrm{n}}$ only when $p \in L-L_{\mathrm{vn}}$. In all other cases, therefore, $\simeq p \in L_{\mathrm{vn}}-\mathrm{v}_{\mathrm{n}}$, and, consequently, $\mathrm{v}_{\mathrm{n}}(\simeq p)=2$. This gives the table for the radical negation.

Now for $\wedge$ and $\vee$. We keep definition (41), according to which for any $v_{\mathrm{n}} \in \mathrm{U}$ and any $p, q \in L, p \wedge q \in \mathrm{v}_{\mathrm{n}}$ iff $p \in \mathrm{v}_{\mathrm{n}}$ and $q \in \mathrm{v}_{\mathrm{n}}$, and $p \vee q \epsilon$ $\mathrm{v}_{\mathrm{n}}$ iff $p \in \mathrm{v}_{\mathrm{n}}$ or $q \in \mathrm{v}_{\mathrm{n}}$. We still need to specify, however, under what conditions $p \wedge q$ and $p \vee q$ belong to either $L_{\mathrm{vn}}-v_{\mathrm{n}}$ or $L-L_{\mathrm{vn}}$, and will thus be valued " 2 " or " 3 ", respectively. The correct truth-tables are generated, 
as is easily seen, by stipulating that $p \wedge q \in L-L_{\mathrm{vn}}$ (and hence valued "3") iff $p \in L_{\mathrm{vn}}$ or $q \in L-L_{\mathrm{vn}}$, and that $p \vee q \in L-L_{\mathrm{vn}}$ (and is hence valued "3") iff $p \in L-L_{\mathrm{vn}}$ and $q \in L-L_{\mathrm{vn}}$. In all cases where $p \wedge q$ or $p \vee q$ are neither in $v_{n}$ nor in $L-L_{v n}$, they are in $L_{v n}-v_{n}$, and, consequently, valued " 2 ".

There is one interesting corollary that follows immediately from this set-up. It is to do with the presuppositional status of logical truths, or sentences that are always valued " 1 " in any valuation. Logical truths pose a descriptive problem for any purely logical definition of presupposition. Such a definition will say that $p$ presupposes $q$ if and only if, for all $v_{n}$ $\epsilon \mathbf{U}$, if $v_{n}(q) \neq 1$ then $v_{n}(p) \neq 1$ or 2 . As is well-known, definitions of this kind imply that when $q$ is a necessary or logical truth it is not only simply entailed but also presupposed by every sentence in the language. This is an undesirable consequence for reasons of descriptive adequacy: it is nonsense to say that an arbitrary sentence like My uncle is far too fond of carrots presupposes any arbitrary logical truth like Nothing is both alive and not alive. Any sensible theory aiming at analysing and explaining presuppositional phenomena would founder on such cases. This is our main reason for not making "presupposition" a relation in the logic and for speaking only of the "logical property of presuppositions", defined in (33) above. What we see now is that, under the definition for $N L_{\mathrm{vn}}$ as given in (43), no $N L_{\mathrm{vn}}$ can contain any $P L_{t}$, where $t$ is a logical truth, for the simple reason that the condition that $v_{n}(t) \neq 1$ cannot be met. (Note also that for any logical truth $t, P L_{t}=L$, according to (42).) This means that logical truths will never have an influence on the delimitation of any presuppositional sublanguage $L_{\mathrm{vn}}$. The constructive approach thus automatically neutralizes this undesirable side-effect of a purely logical definition of presupposition.

\subsubsection{Valuations under construction}

The notions developed in subsection 2.4.1. can be used without alteration for valuations that are not fully constructed, i.e. valuations with values given for some but not all the sentences of $L$. For example, let $L$ have any large number of atomic sentences, and an infinite number of complex sentences, recursively constructed by means of sentential connectives. Let $v_{n}$ be valued for the sentences $a, b, c, d$ and $e$, and let the following presupposition relations hold: $d\rangle\rangle h ; f\rangle|a ; g \gg\rangle b ; j)\rangle a ; j \gg\rangle$. Suppose $v_{n}$, as constructed so far, looks as follows:

$\mathrm{vn}: \quad$\begin{tabular}{|l|l|l|l|l|l|l|l|l|l}
$a$ & $b$ & $c$ & $d$ & $e$ & $f$ & $g$ & $h$ & $j$ & etc. . \\
\hline 1 & 2 & 1 & 2 & 1 & & & & & \\
\hline
\end{tabular}

Fig. 16: Valuation $\mathrm{v}_{\mathrm{n}}$ under construction. 
Since $d$ )> $h, d \in P L_{h}$, according to (42), and given the value " 2 "' for $d$, it follows that $\mathrm{v}_{\mathrm{n}}(h)=1$. Given that $\left.\left.f\right\rangle\right) a$ (and $f$ has no other presuppositions), $v_{n}(f)=1$ or 2 . However, since $v_{n}(b)=2$ and $g \gg>, v_{n}(g)=3$. Likewise, $v_{n}(j)=3$ on account of one of $j$ 's presuppositions, $b$, being valued " 2 ".

Given the construction of $v_{n}$ as in fig. 16, and given the presupposition relations as specified, we conclude that the presuppositional sublanguage of $v_{n}, L_{v n}$, contains $f$ and $h$, but not $g$ or $j$. As the construction of $v_{n}$ proceeds through the valuation of more and more sentences of $L, L_{\mathrm{vn}}$ will get more and more restricted.

\section{DISCOURSE INCREMENTATION}

\subsection{Some principles of discourse domain construction}

The construction of a valuation serves as a model for the construction of a discourse domain by a speaker. In stringing together successive utterances of sentences, a speaker may be regarded as building up a picture of a partial world, which amounts to saying that he is constructing a valuation. However, since what a speaker does is a cognitive activity, one may expect this activity to exhibit certain features that do not figure in a strictly logical modelling of it. This is indeed what we observe. The building up of a discourse domain is subject to certain constraints not found in the strictly logical account of valuation construction as given in the previous section. In this section we will discuss some of these constraints.

When a speaker is building up a discourse domain $D$ he can be taken to decide what value to assign to specific (non-negative) sentences. If he decides that a sentence $p$ is to be regarded as being true, then $p$ is increment$e d$ in $\mathrm{D}$ in certain specific ways. In section 3.2. more will be said about what incrementation amounts to. Here it suffices to say that, in principle, when $p$ is incremented in $\mathrm{D}$, the main predicate $P$ of $p$ is assigned to the discourse entities ("addresses") representing the arguments of $P$. The increment-value of non-negative $p, \mathrm{i}(p)$, is the specific way in which the information conveyed by $p$ is stored in $D$. This process is based on the semantic analysis of $p$, but not fully determined by it: background and default knowledge play a part as well in determining how $p$ is stored in $D$. The building up of a discourse domain is thus more than simply assigning truth-values to sentences. It also, and centrally, involves a cognitively backed storage procedure, called incrementation. In this respect discourse construction is seen to be essentially richer than valuation construction.

If the speaker decides to present $p$ as being true, $\mathrm{i}(p)$ is incremented in 
D. But if he decides to present $p$ as (minimally) false, i $(p)$, though a possible increment, is not incremented in D but, let us say, "quasi-incremented". By this is meant that $\mathrm{i}(p)$ is excluded from D and stored in a "counter-domain" $\mathrm{D}^{\prime}$. The negation word not triggers this (quasi-)incrementation in $\mathrm{D}^{\prime} . \mathrm{D}^{\prime}$ is under embargo in the sense that its contents is excluded from $D$. The counterpart of $D^{\prime}$ in the constructive model-theory is $L_{\mathrm{vn}}-\mathrm{v}_{\mathrm{n}}$. Yet it will be noted that whereas $L_{v n}-v_{n}$ is a set of sentences, $D^{\prime}$ is a store of (quasi-)increments.

The notions defined in (42)-(44) carry over identically to the construction of discourse domains. The notion of $P L_{q}$ can stand unaltered. So can the notions of $N L_{\mathrm{vn}}$ and $L_{\mathrm{vn}}$, which can be renamed $N L_{\mathrm{D}}$ and $L_{\mathrm{D}}$, respectively. But what we have called the "inner complement", if applied to some $D$, is not a set of sentences but a store of possible but rejected increments, $D^{\prime}$.

The first constraint that is relevant here says that only non-negative sentences are valued by the speaker. If he decides to present a sentence $p$ as false, he does not value not-p as "true". Instead, the sentence which forms the argument of the (highest) negation operator, i.e. $p$, is kept out of $\mathrm{D}$ and relegated to the inner or to the outer complement, depending on the speaker's decision. As has been said, the negation operator is the linguistic element that triggers the argument sentence's exclusion from $D$. The increment function $\mathbf{i}$ applied to a negative sentence $\sim p$ increments $p$ in $\mathrm{D}^{\prime}$. What the radical negation does, we shall see in a moment. Clearly, this constraint does not apply to sentences with a negation operator somewhere further down in their analysis, only to those sentences that have negation as the highest operator.

This constraint throws some light on the fact that in natural language stark successions of the negation word, such as English not, do not occur other than with an echo-effect, in which case the argument sentence of the highest negation is quoted and the highest negation is radical. (We saw in section 1.3. that not is a Positive Polarity Item.)

A second constraint, let us say the sublanguage constraint, says that for the construction of a discourse domain D only those sentences can be considered and processed that belong to the presuppositional sublanguage of $\mathrm{D}$, or $L_{\mathrm{D}}$, to the extent that $L_{\mathrm{D}}$ has been defined given the stage of construction of $D$. This means that sentences that must be radically false given that one or more of their presuppositions have been excluded from $D$ can receive no increment value: the function $i$ is undefined for such sentences (though, as we shall see, it is defined for their quoted forms). These are the sentences that belong to $N L_{\mathrm{D}}$. In the light of this constraint the notion of presuppositional sublanguage gains extra significance.

There is more, however. The sentences of $N L_{\mathrm{D}}$ are not totally forgotten. It is, apparently, possible for a speaker to correct or modify a $D$ post 
hoc. He will do that either because he has second thoughts, or, more likely, because he wishes to correct a $\mathrm{D}$ constructed by an interlocutor. A speaker can thus, in hindsight, include an increment that had been banned, or exclude an increment that had been included. Our observations and analyses now suggest that in the latter case, when a speaker decides to exclude an increment that had already been included in $\mathrm{D}$, he can do one of two things. Either he relegates the increment in question to $\mathrm{D}^{\prime}$, by prefixing the minimal negation (making it clear through some recognizable means that he is carrying out what psychologists call a "repair"). Or he can declare the increment null and void and say that the underlying sentence $p$ belongs to $N L_{\mathrm{D}}$. In the latter case he prefixes the radical negation, thereby relegating the sentence $p$, not the corresponding increment $\mathrm{i}(p)$, to the outer complement of $\mathrm{D}$, i.e. to $N L_{\mathrm{D}}$. When a speaker does that he had better also identify the specific presupposition or presuppositions of $p$ whose increment has to be removed from $\mathrm{D}$ along with $\mathrm{i}(p)$ itself, thereby causing $p$ to belong to $N L_{\mathrm{D}}$. For this to be possible we must assume that it is possible to speak about linguistic elements such as sentences. In other words, we must assume that quoted linguistic elements can figure in sentences, and that the incrementation procedure for such sentences involves the setting up of separate addresses to cater for expressions and not their discourse denotata. This assumption, however, is perfectly reasonable, both from a naive observational point of view and from the point of view of linguistic theory.

The sublanguage constraint, together with the possibility of post hoc correction, is thus responsible for the echo-effect observed in radically negated sentences. A sentence of the form not-p can only be minimally negated, with the incremental effect that $\mathrm{i}(p)$ is added to $\mathrm{D}^{\prime}$. But the negation in a sentence of the form not-" $p$ " is metalinguistic and is used when (the increment of) some presupposition of $p$ is removed from $D$ so that, from then on, $p \in$ $N L_{\mathrm{D}}$. Now an address is set up for the sentence $p$, representing the real world object $p$. Under this address a predication is stored to the effect that the sentence called " $p$ " falls outside $L_{D}{ }^{3}$ In the following section 3.2., we shall be more explicit on this aspect.

This analysis smacks a little of both Van der Sandt's Argument-Split solution, with the echo-operator, and Horn's NEG-split theory with metalinguistic negation. And indeed, it combines elements of both theories, excluding, however, the element that they have in common. Both Horn and Van der Sandt take presuppositions, (scalar) implicatures and implications of style and register appropriateness together and let the metalinguistic negation (which, in Van der Sandt's analysis is the classical negation over the quote operator) extend over these as well as over the sentence proper. In our view this is too gross a measure, since, as we saw in section 1.4.1., denials of implicatures or style or register appropriateness implications are 
presupposition-preserving, whereas presupposition denials leave the implicatures and the style or register implications intact. We therefore set the presupposition denials off, as a separate category, from the other denials. On the other hand we accept the distinction between "straight" negation and metalinguistic negation, and it would seem that, for the latter, the assumption of a quote operator of some kind would be indispensable.

The metalinguistic negation that af fects (scalar) implicatures and/or implications of appropriate selections of style and register operates on sentences with a semantic analysis involving clefting, as illustrated in (29) above. The quoted linguistic element is the predicate of the cleft construction, and the assertion is about proper linguistic selection, as in (47):
a. She doesn't LIKE him. She LOVES him.
b. - [the proper expression * in "she * him" is "likes"]. The proper expression * in "she * him" is "loves".

This presupposes that there is a proper expression to fill the gap in "she * him", and since "proper" implies "true", all presuppositional entailments of "she loves him" are preserved. It is difficult for this use of metalinguistic minimal negation to put quotes around a complete sentence. The only possible choice is for surface constituents to be quoted and placed in predicate position. Sentences of the form not- " $p$ " have no choice but to instantiate radical negation. This fact is no doubt in part responsible for the fact, observed in Section 1.3., under B, that the radical negation can occur only in the canonical position of its sentence. The radical negation is sentence negation, but not in the ordinary way, whereby, in terms of Boolean modeltheory, the semantic value of the argument sentence is converted into its complement, but in a special reserved sense in which the argument sentence is taken as its own name, and the negation assigns it the property of belonging to $N L_{\mathrm{D}}$.

This implies a two-dimensional matrix for the possible uses of negation, as in fig. 17:

\begin{tabular}{l|c|c|} 
& $\begin{array}{l}\text { minimal } \\
{[+\mathbf{i}]}\end{array}$ & $\begin{array}{l}\text { radical } \\
{[-\mathbf{i}]}\end{array}$ \\
\hline "straight" $[+\mathbf{i}]$ & + & \\
\hline metalinguistic & + & + \\
\hline
\end{tabular}

Fig. 17: The different uses of negation. 
The feature $[+/-\mathbf{i}]$ indicates whether incrementation under negation results in a "straight" (quasi-)increment or in a quoted sentence being treated as a discourse object. The presupposition-denying radical negation must result in the quoted sentence treatment due to the sublanguage constraint for discourse domains. The presupposition-preserving minimal negation, however, results in "straight" increments, relegating them to $\mathrm{D}$ '. Moreover, "straight", non-metalinguistic negation also results in "straight" increments, and not in the quoted sentence treatment, because if it did it would be metalinguistic by definition. As a result the box for "straight" radical negation must remain empty, since the sublanguage constraint does not allow incremental results for sentences of $N L_{\mathrm{D}}$, other than by predicating this property of " $p$ ".

Approaches like those of Horn or Van der Sandt have the great methodological merit of applying Occam's razor to the process of theory building. This razor cuts growth wherever that is practicable in the light of the available factual data. It must, however, refrain from cutting when the data stand in the way. (It's all right to cut the stubble, but the face must be spared.) My contention is that, as so often, especially in the human sciences, careful observation of the material forces us to enrich the theory, leaving less scope for Occam's razor to do its cutting.

There are, of course, other constraints for the construction of discourse domains. A prominent one among them is the presupposition first constraint, which dictates that for any sentence $q$ which is also an incrementation unit, and for any sentence $p \in P L_{q}, \mathrm{i}(q)$ must precede $\mathrm{i}(p)$ in the construction of any $D$. This means that a partially constructed valuation like the one presented in fig. 16 cannot correspond to a real $D$ under construction, because $d$ has already been valued ("2"), but its presupposition $h$ is still up for valuation. In any real $\mathrm{D}, \mathrm{i}(h)$ would have been slipped in before $\mathrm{i}(d)$.

The presupposition first constraint applies to incrementation units, which do not necessarily coincide with sentences. Conjunctions, in particular, seem not to function as single incrementation units, though we must consider them, of course, to form single but complex sentences. The central presuppositional problem with conjunctions is that sentences of the form $p$ and $a_{p}$ (i.e. $p$ conjoined with $a$ presupposing $p$, as in " $\mathrm{He}$ is a crook, and you know it") both assert and presuppose $p$ if we treat them as single incrementation units. This is counterintuitive and counterproductive, since it requires that we have $\mathrm{i}(p)$ first, to be followed by $\mathrm{i}(p$ and $q)$, which results anyway in $\mathbf{i}(p)$ followed by $\mathbf{i}(q)$. The result would be a pointless repetition of $\mathbf{i}(p)$. For that reason we stipulate that the conjuncts of a conjunction form separate incrementation units. Now $p$ and $a_{p}$ results simply in $\mathrm{i}(p)$ followed by i $(q)$. (For more discussion see Seuren 1985: 280-284.)

It is, however, not our business here to develop a complete theory of Dconstruction, and we shall now pass on to the question of the actual incrementation result of negative sentences. 


\subsection{The incrementation of negation}

If a discourse domain is $\mathrm{D}$ to be an adequate storage for the information conveyed by successive sentences in a discourse, it must possess a fairly complex array of storage methods. Even if we assume, as we do, that the information stored in a D is purely structural and thus excludes lexical semantic analyses or encyclopaedic knowledge about the things talked about, it still requires quite complex management procedures, which it cannot be our purpose here to specify in full. What is required in any case is a set of addresses accumulating the information provided of the individuals that figure in the discourse. There will be singular and plural addresses, and other kinds as well. (Thus, for example, addresses must be made available for the facts that are being talked about.) Moreover, $\mathrm{D}$ must provide the means for containing instructions relating to the further development of $D$. These instructions are expressed linguistically through "technical" operators such as not, and, $o r$, or if, the quantifiers, or any predicate, such as believe, that introduces an intensional subdomain.

What interests us here is the way not determines the incrementation result of its argument. To illustrate this, let us take the case of a simple sentence like (48a), with its minimal negative counterpart (48b):

a. The car hit the curb.

b. The car did not hit the curb.

For these sentences to be processes in some D, D must contain addresses for the terms the car and the curb, with at least the following information:

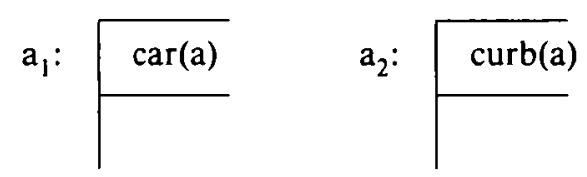

(The horizontal line underneath the predications "car(a)" and "curb(a)" indicates "address closure", an operation required for referential correctness (see Seuren 1985: 317-319). We will not expand on this aspect of the theory here. Yet the closure operation will be mentioned wherever appropriate.) The incrementation of (48a) now results in the addition of the predication "hit $\left(a_{1}, a_{2}\right)$ " to both addresses (whereby the non-subscripted " $a$ " stands for the address in question):

$$
a_{1}: \sqrt{\frac{\operatorname{car}(a)}{\operatorname{hit}\left(a, a_{2}\right)}} \quad a_{2}: \sqrt{\frac{\operatorname{curb}(a)}{\operatorname{hit}\left(a_{1}, a\right)}}
$$


(No account is taken of tense or aspect phenomena. Speech act properties are also disregarded, as well as other possible factors that should be taken into account in a fully developed incrementation procedure.)

The minimally negative (48b) is incremented in much the same way as (48a), but with the extra condition that the increment is to be stored not in $\mathrm{D}$ but in the counter-domain $\mathrm{D}^{\prime}$. This must be indicated formally, for example by asterisking the negated predications:

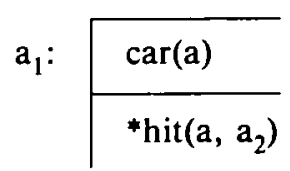

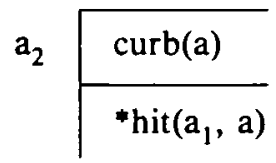

D now contains the instruction that the predication "hit $\left(\mathrm{a}_{1}, \mathrm{a}_{2}\right)$ " is ostracised as an increment for the duration of $D$.

An analogous procedure is followed when the setting up of a new address is banned and relegated to $D^{\prime}$. A new address is set up in one of two ways. The canonical way is through the occurrence of an existential quantifier at the top of the semantic analysis of the sentence to be incremented, as in (49a) with the semantic analysis (49b):

a. A car drove past.

b. $\left.31[x(\operatorname{drive} \operatorname{past}(\mathrm{x})))^{\wedge} \mathrm{x}(\operatorname{car}(\mathrm{x}))\right]$

In (49b) the existential quantifier " $\exists 1$ " functions as a technical higher order binary predicate over pairs of sets, the first set consisting of the individuals that "drive past", the second set being the set of cars. The satisfaction condition associated with this predicate is, simply, that the two sets have an intersection of at least one individual. The existential predicate is "technical" because its increment value is non-standard. The resulting increment consists, in fact, in the setting up of a new singular address:

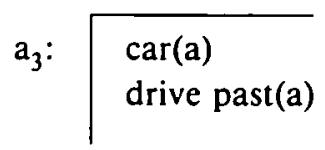

(A new address set up in this way is not closed by the horizontal line: it will be as soon as a subsequent definite term denotes it. "Open" addresses are satisfied by anything in the model (world) that answers the description stored in the address. Open addresses thus have a truth-value: they can be true or false (or truthvalueless if no verification domain is specified). Closed addresses are cognitively fixed onto a specific individual or set of individ- 
uals.) The (minimal) negation of $(49 a)$ is $(50 a)$, with the analysis (50b):
a. No car drove past
b. $\quad \exists 1\left[\mathrm{x}(\operatorname{drive} \operatorname{past}(\mathrm{x})),{ }^{\wedge} \mathrm{x}(\operatorname{car}(\mathrm{x}))\right]$

The resulting increment is like that of (49b), except for the asterisk which indicates that this increment, though otherwise in order, is relegated by the speaker to $D^{\prime}$ :

$$
\begin{array}{ll}
* a_{3}: & \begin{array}{l}
\text { car(a) } \\
\text { drive past(a) }
\end{array}
\end{array}
$$

The second way of setting up a new address is by means of so-called "post hoc suppletion" (also called "backward suppletion" or "accommodation"). This takes place when the text contains no explicit existential statement, but only a definite description without, as yet, a corresponding domain address. When available background knowledge supports the setting up, post hoc, of a proper address for the definite term to "land at", that is what happens. Thus, when I begin a story uttering (48a), without first properly introducing the car I am speaking about (for example by saying something like As I was taking my morning stroll, a car drove past), post hoc suppletion quickly slips in a car-address, as though I had actually uttered an existential statement. Addresses set up as a result of post hoc suppletion are immediately closed, simply because they are immediately denoted by a definite term.

This apparatus suffices, in principle, for the minimal negation. It caters for the Horn cases if provisions are made for the accommodation of quoted elements. Suppose someone says (51a) and I say, correcting the previous speaker, (51b) with the semantic analysis (51c):
a. She took some of it.
b. No, she didn't take SOME of it. She took ALL of it.
c. - [be "some" (the proper expression * in "She took * of it)]; be "all" (the proper expression * in "She took * of it")

When (51b) is up for incrementation, a new address is slipped in, by backward suppletion, for the definite term the proper expression "in "She took " of it", and this address is immediately closed. Then the predication (be) "some" is added with an asterisk and the predication (be) "all" is added without asterisk:

$$
a_{15}: \begin{aligned}
& \text { proper expression * in "She took * of it" (a) } \\
& \begin{array}{l}
\text { " "some" (a) } \\
\text { "all" (a) }
\end{array}
\end{aligned}
$$


There is thus no question of a sentence like (5lb) being in any way an incompatible conjunction of contrary conjuncts (assuming, reasonably, that the it stands for something real, otherwise the conclusion, in standard predicate calculus, is that she took nothing). The sentence is not, or anyway not directly, about what, if anything, she took, but about what expression describes the situation most adequately. That the semantic analysis takes an unusual form, as in (51c), seems best attributed to the, still largely unknown, peculiarities of the grammar of quotes, and not to an alleged ambiguity of the word not, whether this ambiguity is called pragmatic (as Horn does) or semantic, or logical, or what not.

Now suppose (48b) is to be incremented not with the minimal but with the radical negation:

The car did NOT hit the curb. There was no curb!

For such a pair of sentences to be incremented it is required that $D$ already contains the increment of (48a). The car hit the curb. By way of "repair" the speaker wishes to undo both that increment and the increment consisting in the setting up of address $a_{2}$, the curb-address. This means that $a_{2}$ is asterisked. But now $\mathbf{i}$ (the car hit the curb) is undefined, since one of the presuppositions of that sentence has been banned from $D$ and relegated to $D^{\prime}$. Therefore, the normal method of keeping increments away from $D$, by relegating them to $D^{\prime}$, cannot be followed. The solution adopted by the human linguistic faculty is, apparently, to quote the sentence in question, instead of taking the increment, and assigning to that sentence the property of belonging to $N L_{\mathrm{D}}$. The sentence thus remains without its standard increment value, but it is incremented as an address in $D$, denoted by its quoted form (its name). The result looks something like the following: ${ }^{4}$

$$
a_{36}: \sqrt{\text { "the car hit the curb" (a) }}
$$

This analysis clearly implies a truth-conditional difference between minimal and radical not, and hence a semantic ambiguity. A minimally negative sentence not-p is true just in case the preconditions of the highest predicate $P$ of $p$ are fulfilled, but not the satisfaction conditions of $p$. The radically negative not- " $p$ " is true just in case the sentence $p$ does not belong to the presuppositional sublanguage of the $D$ in question, i.e. there is presupposition failure resulting from non-fulfilment of the preconditions of $P$. As we have seen, this truth-conditional difference is neatly expressed in terms of a three-valued logic. Such a logic, however, is nothing but a statement of the logical properties of the system at hand. It is not by itself a description of the system. 
This ambiguity, however, is quite unlike any arbitrary lexical ambiguity that may occur in a language, such as the ambiguity of the English noun plant, which is ambiguous between a botanical object and a complex of buildings and constructions intended for industrial production. As ambiguities go, the ambiguity of not is highly idiosyncratic, in that it is not haphazard but manifests different methods of banning increments from $D$. We may say that the increment function $\mathrm{i}$ contains a negation algorithm, roughly and incompletely characterized as follows:

For any sentence with not as the highest operator, not takes the "straight" increment $i(p)$ of its argument $p$ or " $p$ ". If the argument is $p$, not assigns i $(p)$ to $\mathrm{D}^{\prime}$. If the argument is " $p$ ", not assigns the predication " $N L_{\mathrm{D}}$ (a)" to the address $\mathrm{a}_{\mathrm{n}}$ set up (post hoc) as the denotation of the name " $p$ ". In that case, there must be some $\mathrm{i}(q)$ in $\mathrm{D}$, such that $p \gg q$, and not- $q$ must be processed.

As has been said above, it is like theft being either a felony or a misdemeanour: in either case there is illegal taking possession of goods. Here we have minimal and radical negation. In either case there is failure of predicate conditions, and in either case there is banning of an increment from $D$. Moreover, the increment function $i$ is organized in such a way that, given some appropriate $\mathrm{D}$, the question of whether not takes $p$ or " $p$ " as argument is automatically settled. If $p$ belongs to $L_{\mathrm{D}}$, then not takes unquoted $p$ as its argument, resulting in $\mathrm{i}(p)$ becoming part of $\mathrm{D}^{\prime}$. But if the speaker decides to revise $\mathrm{D}$ so as to make $p$ belong to $N L_{\mathrm{D}}$, not has no choice but to take " $p$ " as its argument, with the quotes. Thus used, not assumes different truth-conditions.

It is not possible to say that this explains why natural languages tend not to have separate words for minimal and radical negation, since, clearly, we have as yet no general theory that will predict for special cases such as negation whether or not overt disambiguation will take place. All we can do at this stage is say, in hindsight, that, given the close relationship between the two meanings of not, given the automatic selection, in any D, of the proper reading, and given the strongly marked character of radical not, there is, apparently, no need for disambiguation. ${ }^{5}$ Gazdar's objection (quoted in note 2 above), that negation is unlikely to be ambiguous because languages tend not to disambiguate it, is reasonable and must be answered. The answer we can give now is that, given the analyses presented above, one is justified in saying that this objection need not cause too much concern. We now know that negation is sufficiently different from ordinary cases of lexical ambiguity for this objection to lose most if not all of its force. Later research will hopefully show whether negation is unique in this respect, or whether it does, after all, fit into a more general pattern. 


\subsection{The empirical value of logical analysis}

We can now be more specific about the relation between the logic that goes with the incremental system and the system itself, and in particular about the empirical relevance of logic for an adequate semantic analysis. Let us consider a few examples not directly related to negation. It has been said above (section 1.4.2.) that truth-conditional differences may be involved in the ordering of conjuncts. This is so when the conjuncts express successive events (they have aorist aspect). In those cases there is a clear difference between $p$ and $q$ on the one hand, and $q$ and $p$ on the other:

a. He made a fortune and went to Spain.

b. He went to Spain and made a fortune.

It is not too difficult to see that, in principle, a discourse incrementation system will be able to take care of this. Discourse semantics will have to provide procedures for the proper incrementation of time-bound sentences, i.e. for the expression of tense and aspect. It will be part of such procedures to provide some indexing method for predications under addresses with regard to their ordering in time. The relative indexings of the conjuncts will then express this difference, and the truth-conditions for the conjunction as a whole will differ accordingly.

There is thus no doubt that the difference between (aorist) $p$ and $q$ and $q$ and $p$ is fully truth-conditional. One may still wonder whether, in that case, natural language and in conjunctions under aorist tense is not truthfunctional. But this conclusion is not warranted since the time indexings of each conjunct are part of their truth-conditions, so that, with the proper indexings, $p \wedge q$ is equivalent to $q \wedge p$, where $p$ and $q$ are truth-conditionally correct logical analyses, and $\wedge$ is the logical conjunction operator. Even so, however, the fact remains that $p$ and $q$, where $p$ and $q$ are sentences, is not equivalent to $q$ and $p$. If the order of the sentences is inverted, different propositions come about, as a result of the now different time indexings. In other words, once logical $p \wedge q$ has been expressed as $p$ and $q$, logical $q \wedge p$ can no longer be expressed linguistically. This is a semantic property of natural language conjunctions, which is not reflected in standard propositional calculus, with truth-functional and symmetrical and. It is perhaps possible to develop a propositional calculus that behaves in a way that is strictly parallel to what is found in language, but that logic would have no other purpose than to reflect what happens in language. Useful though such an exercise is for a better understanding of language, no intrinsic logical purpose is served by it. It would be an exercise in applied logic, not in pure logic.

A similar pattern emerges when the other traditional truth-functional 
operators of standard propositional calculus are considered. The increment value of and, as we have seen, consists in the incrementation of its conjuncts in the order in which they occur in the sentence (whereby each conjunct is a separate unit of incrementation). The disjunction operator or has the effect of splitting up D into as many subdomains as there are disjuncts, this splitting being marked as a commitment, on the part of the speaker, that at least one of the disjuncts/subdomains is to be added as part of D. Implications of the form if $p$ then $q$ have the incremental effect of stipulating (as a domain instruction) that $i(p)$ is not to be excluded from $D$ but that it is allowable only if conjoined with $\mathbf{i}(q)$.

Interestingly, natural language grammars provide no way to express the normal, non-contrastive, non-radical negation of conjunctions, disjunctions and implications other than by the prefixing of "it is not the case that" or some similarly artificial periphrastic, involving separate incrementation procedures under predicates like "be the case that". Apparently, not is defined only for increments, whether new or already processed and now reprocessed. And apparently, it is not only conjuncts that form separate incrementation units but also disjuncts and the clauses of implications. These are aspects, however, that we cannot investigate more fully here.

What, then, is the empirical value of logical systems that aim at incorporating, as much as possible, the quirks of natural linguistic interpretation processes? In at least one respect this value is clear. Any logical system requires the setting up of well-defined logical analyses that function as units in the logic machinery. To the extent that a logic mirrors natural language processes more faithfully, one is more justified in claiming that the logical analyses figuring in it embody structural and semantic constraints on the semantic analyses to be provided by the grammar for the sentences of the language. In this way, the logical system shows up the logical conditions that must be fulfilled by any semantic theory, besides the other conditions that must be met. But there can be no question of the logical system itself being part of the semantic machinery of cognitive processing of uttered sentences. All one can demand is that the structural and logical properties of the analyses that occur in the logic be somehow incorporated into the semantic analyses and definitions of sentences and words occurring in them, so that the semantic theory is kept logically sound.

This shows again that, in language, logic is epiphenomenal on the structures and processes that occur in the semantic and cognitive processing of uttered sentences. Existing logical analyses only do partial justice to the reality of language, and in some cases, such as disjunction and implication, they actually distort it. Obviously, attempts at developing sound logics that do fuller justice to language are to be welcomed and appreciated if only because they attempt to show the logical soundness of language. Yet, no matter how well they fit the facts of language, any claim to the effect that the logical 
properties of the expressions figuring in them (such as monotonicity, to take just an example) are relevant to the empirical study of meaning phenomena will have to be argued for separately and independently. This, then is the status claimed for the three-valued logic with its two negations described above: it appears to provide a logical account of the presuppositional differences of minimal and radical negation. If the logical analysis is correct and the observations on which it is based reflect linguistic reality, semantic analyses of sentences are constrained by this logic, and minimal and radical negation must both be assumed to occur in negative sentences.

Nijmegen University

Philosophy Institute

P.O. Box 9108

6500 HK NIJMEGEN-Holland

\section{NOTES}

1. For further details, see Seuren (1985: 217).

2. Cp. Gazdar 1979: 65-6: "But no language, to the best of my knowledge, has two or more different types of negation such that the appropriate translation of (11) [ = John doesn't regret having failed] could be automatically 'disambiguated' by the choice of one rather than the other."

3. Natural language happily mixes object and metalanguage. The Liar paradox and its kin are obviated by other means than the strict separation of object and metalanguage (cp. Seuren to appear).

4. This way of incrementing radically negated sentences differs from what is proposed in Seuren (1985: 331), where the double asterisk is used to mark radical negation. The proposal made here is more explanatory and based on a more careful analysis, prompted to a large extent by the works of Horn and Van der Sandt.

5. One may well wonder what happens in languages, such as Turkish, with morphologically incorporated negation. According to $A$ in section 1.3, morphologically incorporated negations are necessarily presupposition-preserving. One would, therefore, expect such languages to have a separate negation word to be used when radical negation is called for. Turkish has, besides the bound morpheme $m V$ (i.e. with a vowel that follows vowel harmony), also the word degil. It remains to be seen whether degil is required for radical negation, besides its other functions in the language.

\section{REFERENCES}

Baker, C.L., 1970: Double negatives Linguistic Inquiry 1.2: 169-86.

Blau, U., 1978: Die dreiwertige Logik der Sprache. Ihre Syntax, Semantik und Anwendung in der Sprachanalyse. De Gruyter, Berlin-New York.

Bochvar, D.A., 1939: On a three-valued logical calculus and its application to the analysis of the paradoxes of the extended functional calculus (Russian). Matematiceskij Sbornik, N.S.: 4: $287-308$.

Boêr, S. and Lycan, W., 1976: The myth of semantic presupposition. Indiana University Linguistics Club.

Donnellan, K., 1966: Reference and definite descriptions. Philosophical Review. 75: 281-304.

Frege, G., 1982: Über Sinn und Bedeutung. Zeitschrift für Philosophie und philosophische Kritik. 100: 25-50.

Gazdar, G., 1979: Pragmatics: Implicature, Presupposition, and Logical Form. Academic Press, New York-San Francisco-London. 
Grice, H.P., 1967: Logic and conversation. The William James Lectures. Harvard University. Unpublished.

Horn, L.R., 1985: Metalinguistic negation and pragmatic ambiguity, Language. 61.1: 121-174.

Kartunen, L. and Peters, S., 1979: Conventional implicature. In: Ch.-K. Oh \& D.A. Dinneen (eds.), Presupposition (= Syntax and Semantics 11), Academic Press, New York-San Francisco-London: 1-56.

Russell, B., 1905: On denoting, Mind 14: 479-93.

Seuren, P.A.M., 1985: Discourse Semantics. Blackwell, Oxford.

Seuren, P.A.M., to appear: Les paradoxes et le langage. Logique et Anolyse.

Strawson, P.F., 1950: On referring. Mind 59: 320-44.

Strawson, P.F., 1952: Introduction to Logical Theory. Methuen, London.

Strawson, P.F., 1954: A reply to Mr Sellars. Philosophical Review 63.2: 216-31.

Van der Sandt, R.A. 1982: Kontekst en Presuppositie: Een studie von het projektieprobleem en de presuppositionele eigenschappen van de logische konnektieven. PhD-thesis. Nijmegen.

Van der Sandt, R.A., 1988: Context and Presupposition. Croom Helm, London-New YorkSydney.

Van der Sandt, R.A., to appear: Discourse systems and echo-quotation.

Van Fraassen, B., 1971: Formal Semantics and Logic. Macmillan, New York-London.

Weijters, A., 1985: Appendix: Presuppositional propositional calculi. In: Seuren 1985: 483-525.

Wilson, D., 1975: Presuppositions and Non-Truth-Conditional Semantics. Academic Press, London-New York-San Francisco. 